\title{
EXPRESSION OF PHENAZINE BIOSYNTHETIC GENES DURING THE ARBUSCULAR MYCORRHIZAL SYMBIOSIS OF GLOMUS INTRARADICES
}

\author{
Dionicia Gloria León-Martínez ${ }^{1,2}$, Jean-Philippe Vielle-Calzada $^{2^{*}}$, Víctor Olalde-Portugal $^{1}$ \\ ${ }^{1}$ Laboratorio de Bioquímica Ecológica. Centro de Investigación y Estudios Avanzados del IPN. CP 36821, Irapuato Guanajuato, \\ México; ${ }^{2}$ Grupo de Desarrollo Reproductivo y Apomixis. Departamento de Ingeniería Genética de Plantas y Laboratorio Nacional \\ de Genómica para la Biodiversidad, Centro de Investigación y Estudios Avanzados, CP 36821, Irapuato Guanajuato, México.
}

Submitted: July 14, 2011; Returned to authors for corrections: August 15, 2011; Approved: June 07, 2012.

\begin{abstract}
To explore the molecular mechanisms that prevail during the establishment of the arbuscular mycorrhiza symbiosis involving the genus Glomus, we transcriptionally analysed spores of Glomus intraradices BE3 during early hyphal growth. Among 458 transcripts initially identified as being expressed at presymbiotic stages, $20 \%$ of sequences had homology to previously characterized eukaryotic genes, $30 \%$ were homologous to fungal coding sequences, and $9 \%$ showed homology to previously characterized bacterial genes. Among them, GintPbrla encodes a homolog to Phenazine Biosynthesis Regulator (Pbr) of Burkholderia cenocepacia, an pleiotropic regulatory protein that activates phenazine production through transcriptional activation of the protein D isochorismatase biosynthetic enzyme phzD (Ramos et al., 2010). Whereas GintPbrla is expressed during the presymbiotic phase, the G. intraradices BE3 homolog of phzD $(\mathrm{BGintph} z D)$ is transcriptionally active at the time of the establishment of the arbuscular mycorrhizal symbiosis. DNA from isolated bacterial cultures found in spores of $G$. intraradices BE3 confirmed that both $\mathrm{BGintPbrla}$ and $\mathrm{BGintph} z \mathrm{D}$ are present in the genome of its potential endosymbionts. Taken together, our results indicate that spores of $G$. intraradices BE3 express bacterial phenazine biosynthetic genes at the onset of the fungal-plant symbiotic interaction.
\end{abstract}

Key words: mycorrhizal fungi, Glomus intradices, phenazine, biosynthesis.

\section{INTRODUCTION}

The arbuscular mycorrhiza (AM) is a complex and intimate association of organisms formed by fungi of the Glomeromycota phylum and different taxonomic groups of plants, including $80 \%$ of the terrestrial flora (Schüssler et al.,
2001; Smith and Read, 1997). After the consistent discovery of endocellular bacteria within mycorrhizal fungi (Macdonald M.R. and Chandler R.M. 1981; Bianciotto et al., 1996), AM has been considered to be the result of a tripartite symbiosis (Bonfante, 2003). The absence of these bacteria from fungal spore, results in important changes in fungal

*Corresponding Author. Mailing address: Grupo de Desarrollo Reproductivo y Apomixis. Departamento de Ingeniería Genética de Plantas y Laboratorio Nacional de Genómica para la Biodiversidad, Centro de Investigación y Estudios Avanzados, CP 36821, Irapuato Guanajuato, México.; Fax.: 52-462-623-5849.; E-mail: vielle@ira.cinvestav.mx 
presymbiotic growth and sporal morphology, suggesting that they are important for mycellium germination and possibly ecological fitness (Lumini et al., 2007); however, their main role during the establishment and maintenance of the AM symbiosis remains unknown. Studies attempting to elucidate their physiological role have been hindered by a lack of protocols allowing their cultivation in vitro (Bianciotto et al., 2004; Bonfante and Anca, 2009), a difficulty that could be related to the impossibility of reproducing essential conditions of the fungal cytoplasmic milieu necessary for their survival (Jargeat et al., 2004).

Some understanding of the role played by non-AM bacterial endosymbionts has emerged from studies of plant pathogenic fungi belonging to the genus Rhizopus, in which the antimitotic polyketide rhizoxin - responsible for causing seedling blight in rice - is biosynthesized by bacteria of the genus Burkholderia (Partida-Martínez and Hertweck, 2005). Rhizopus microsporus does not form sporangia and spores in the absence of its endosymbionts, indicating that Burkholderia produce metabolic factors that are essential for the fungal life cycle (Partida-Martínez et al., 2007). In addition to confirming the potential for a large genetic diversity intrinsic to Burkholderia and perhaps other families of endosymbiotic bacteria (Komatsu et al., 2003), the recent elucidation of a Burkholderia rhizoxinica genome revealed an evolutionary tendency not only towards specialized uptake of fungal metabolites, but also to a bacterial-dependent provision of putative phytotoxins and virus-related factors that could promote nutritional uptake from decaying plants (Lackner et al., 2011). The phenotypic diversity of endosymbionts is also reflected by their capacity for producing a large variety metabolites involved in antagonistic interactions such as phenazines, a large family of heterocyclic nitrogen antibiotical compunds produced by different bacteria such as Burkholderia, Streptomyces and Pseudomonas ssp., but not animals or plants (Thomashow and Weller, 1988; Komatsu et al., 2003; Delaney et al., 2001; Blankenfeldt et al., 2004; Laursen and Nielsen,
2004; Fitzpatrick, 2009).

In contrast to non-AM endocellular bacteria, the genetic diversity, metabolic potential, and physiological contribution of AM endosymbionts remains largely unexplored. Endocellular bacteria have been reported in several Glomeromycota species that include Glomus versiforme, Acaulospora laevis, and Gigaspora margarita (MacDonald and Chandler, 1981; Bianciotto, 2000; Naumann, 2010), as well as the ectomycorrhizal basidiomycete Laccaria bicolor for which a complete genome is available (Bertaux et al., 2003; Martin et al., 2008). In several Gigaspora species, rod-shaped Gram negative endosymbiotic bacteria were demonstrated to be present in spores, germ tubes, and hyphae, but not arbuscules (Bianciotto et al., 1996). A genomic library of G. margarita had a partial representation of the genome of its bacterial endosymbionts (van Buuren et al., 1999), and although subsequent studies suggested that some sequences could have resulted from contamination with foreign bacterial DNA (Jargeat et al. 2004), a gene encoding a putative phosphate transporter, and a gene involved in cell colonization by enteroinvasive pathogenic bacteria were unequivocally confirmed as being derived from genetic material contained in the spores $G$. margarita (Ruiz-Lozano and Bonfante, 1999; Anca et al., 2009), demonstrating the presence of bacterial DNA within the fungus.

Here we analyze a sample of cDNA clones generated from mRNA present in Glomus intraradices BE3 prior to the establishment of the AM symbiosis, identifying numerous transcripts with homology to eukaryotic or prokaryotic genes. We show that a gene with homology to the bacterial pleiotopic regulator Phenazine Biosynthesis Regulator $(\mathrm{Pbr})$ is expressed within fungal cells at presymbiotic stages, and present in genomic DNA samples extracted from bacterial isolates cultivated from Glomus intraradices BE3 spores. We also show that a homolog of the bacterial phenazine biosynthetic gene $p h z D$ - also present in the genome of bacterial isolates from Glomus intraradices BE3 spores - is expressed at the time 
of the establishment of the fungal-plant symbiosis. Our results indicate that phenazine biosynthetic genes are active in $G$. intraradices $\mathrm{BE} 3$, opening possibilities for studying its function and regulatory mechanisms during the AM symbiosis.

\section{MATERIALS AND METHODS}

\section{Mycorrhizal material}

Spores of Glomus intraradices strains BE2 and BE3 were obtained from the in vitro collection of Departamento de Biotecnología y Bioingeniería CINVESTAV Zacatenco, and recovered following chelation with sodium citrate as described in Doner and Bécard (1991). Spores of Gigaspora margarita BE2 were isolated from potted plant trap cultures with Sorghum sp. and Lolium sp., following the method of tweensucrose flotation (Gerdemann and Nicholson, 1963).

\section{cDNA library construction and sequencing}

Spores of $G$. intraradices BE3 were germinated in the presence of Ri T-DNA transformed roots of carrot. No physical interaction was allowed by insertion of a cellophane membrane between the fungus and plant tissues. Germinated spores were recovered with insulin syringes (Beckton-Dickinson) under a stereo-microscope and immediately frozen in liquid nitrogen. Total RNA was obtained using the RNAeasy mini kit (Qiagen) and treated with RNase-free DNase I according to manufacturer's instructions (Invitrogen). Total RNA was quantified by NanoDrop® ND-1000 (Spectrophotometer Termo Scientific), and PCR-tested for integrity using primers r18S and f18S (sequence available in Supplementary Materials).

Total RNA concentration was adjusted to $450 \mathrm{ng}$ and used for cDNA synthesis using a CDS III/3' PCR primer [5'ATTCTAGAGGCCGAGGCGGCCGACATG-d(T)30-(A,G,C) -(A,G,C,T)-3'] and the SMART kit (Clonetech). Doublestranded cDNA was purified and cloned into pCR 2.1 TOPO (Invitrogen). A random sample of 960 cDNA clones was sequenced using M13 forward and reverse primers and the Terminador Bigdye kit (ABI). Resulting sequences were assembled and filtered using parameters of minimum overlap 25 , maximum gap 2, minimum overlap identity $80 \%$, and maximum ambiguity 4 (Drummond et al., 2010. Geneious v 5.0); sequences representing unique genes, were compared to entries of the NCBI database using the non-redundant BLASTX algorithm (Worley et al,. 1995).

\section{Fungal spore cultivation}

Spores of $G$. intraradices BE3 were recovered from petri dishes divided by $10 \mathrm{mM}$ sodium acetate. Spore disinfection was performed with $0.05 \%$ Tween $20,2 \%$ chloramine $\mathrm{T}$ twice for 5 minutes, followed by 3 rinses in sterile distilled water. Samples were subsequently stored in a 100 ppm of gentamicin, $200 \mathrm{ppm}$ streptomycin solution at $4^{\circ} \mathrm{C}$ (Bécard and Piché, 1992). For spore bursting and bacterial isolation, approximately 500 spores/plate were inoculated in minimal mineral media (M) medium (Fortin et al., 2002), in the absence of sucrose and following a $\mathrm{pH}$ gradient from 3 to 10 with increments of 0.5 units. Three replicates of each plate were incubated at $25^{\circ} \mathrm{C}$ until spore bursting and bacterial growth occurred. Successfully isolated bacterial colonies were transferred into two different culture media: a rich Bacto Nutrient Agar culture medium (Difco), and a poor M culture medium containing sucrose and potato dextrose agar (Bioxon), and subsequently cultivated in Bacto Nutrient broth culture for DNA extraction following Harwood and Cutting (1990). FD1 and RD1 primers were used for $16 \mathrm{~S}$ rDNA PCR amplification (Weisburg et al., 1991) and PCR products were cloned into the pCR 2.1 TOPO vector and sequenced by Sanger. Sequence comparisons were conducted following conventional BLAST algorithms (Worley et al,. 1995). Closely related sequences were analyzed using Geneious 5.0 under a Tamura-Nei genetic distance model, (Drummond et al., 2010; Geneious v 5.0). New DNA sequences were deposited in the National Center for Biotechnology Information database (NCBI). 


\section{RT-PCR}

Total RNA was extracted from growing hyphae using TRIzol (Invitrogen). Reactions were performed using One-Step RT-PCR kit (QIAGEN) and the annealing temperature was standardized for each pair of primers used (Supplementary Table 2). In all cases reverse-transcription reactions were performed with 3 biological replicates representing independent events, using $100 \mathrm{ng}$ of total RNA and 50 pmoles/ $\mu$ l of each primer. PCR conditions were 1 minute at $94^{\circ} \mathrm{C}$ (denaturation), 30 seconds at $55-60^{\circ} \mathrm{C}$ (alignment), $1 \mathrm{~min}$ at $72^{\circ} \mathrm{C}$ (extension) for 28 cycles, followed by a final extension at $72^{\circ} \mathrm{C}$ for 5 minutes.

\section{RESULTS}

Transcripts with homology to eukaryotic or prokaryotic genes are expressed at pre-symbiotic stages of the $G$. intraradices BE3 life cycle

To conduct a transcriptional analysis of AM spore germination and early hyphal growth, we constructed a cDNA library using mRNA from an in vitro culture of $G$. intraradices
BE3 at asymbiotic to presymbiotic stages, in the absence of physical interaction with plant tissues (D.G. León-Martínez, JPh. Vielle-Calzada, and V. Olalde-Portugal, unpublished results). An initial screen of the $10^{4} \mathrm{col} / \mu \mathrm{g}$ titer colony collection resulted in the identification of 458 distinct open reading frames on the basis of 960 sequenced clones (Supplementary Table 1). A comparison of assembled coding sequences to publically available databases revealed that the corresponding genes encode for a large variety of proteins covering a wide spectrum of predicted molecular functions in eukaryotes. Whereas $20 \%$ of sequences had homology to previously characterized eukaryotic genes, $30 \%$ were homologous to fungal coding sequences, $9 \%$ showed high homology to previously characterized bacterial genes, and $41 \%$ did not show homology with reported genomic sequences. cDNA sequences with homology to bacterial genes encode proteins involved in housekeeping, secondary metabolism or signal transduction pathways, putative transcription factors, or proteins conferring resistance to antibiotics such as tetracycline (Table 1).

Table 1. Identification of sequences with homology to prokaryotic genes and expressed during pre-symbiotic stages of Glomus intradices BE3.

\begin{tabular}{|c|c|c|c|c|}
\hline $\begin{array}{c}\text { Length } \\
\text { (pb) }\end{array}$ & PROTEIN & ORGANISM & Accession number & E-value \\
\hline 635 & PBR & Burkholderia cenocepacia & ACJ54935 & $1.15 \mathrm{e}-11$ \\
\hline 647 & hypothetical protein & Clostridium nexile & ZP_03289628 & $2.71 \mathrm{e}-31$ \\
\hline 813 & hypothetical $16.9 \mathrm{~K}$ protein & Salmonella typhimurium & JQ1541 & $8.72 \mathrm{e}-40$ \\
\hline 269 & hypothetical protein & Azorhizobium caulinodans & YP_001526574 & $5.88 \mathrm{e}+00$ \\
\hline 437 & hypothetical protein & Bacteroides uniformis & ZP_02071990 & $9.91 \mathrm{e}+00$ \\
\hline 439 & $\begin{array}{l}\text { helix-hairpin-helix DNA-binding motif-containinG } \\
\text { protein }\end{array}$ & Methylobacterium sp. & YP_001772034 & $2.77 \mathrm{e}-02$ \\
\hline 230 & oxidoreductase aldo/keto reductase family 1 & Vibrio coralliilyticus & ZP_05886239 & $2.84 \mathrm{e}-02$ \\
\hline 235 & NADH pyrophosphatase & Vibrio splendidus & ZP_00991846 & $2.64 \mathrm{e}+00$ \\
\hline 288 & GGDEF domain protein & Desulfovibrio magneticus & YP_002953232 & $7.77 \mathrm{e}+00$ \\
\hline 421 & hypothetical protein & $\begin{array}{l}\text { Salmonella enterica subsp. arizonae serovar } \\
62: \mathrm{z} 4, \mathrm{z} 23\end{array}$ & YP_001571636 & $2.03 e+00$ \\
\hline 538 & Tetracycline resistance protein & Bacillus cereus & ZP_04234556 & $8.92 \mathrm{e}-01$ \\
\hline 528 & putative nitrogen metabolite repression regulator & Rhizobium leguminosarum bv. viciae & YP_766861 & $5.57 \mathrm{e}-08$ \\
\hline 262 & arginine biosynthesis bifunctional protein $\mathrm{ArgJ}$ & Clostridium papyrosolvens & ZP_05498017 & $6.74 \mathrm{e}-04$ \\
\hline 335 & hypothetical protein BDI & Parabacteroides distasonis & YP0130449_03 & $6.89 \mathrm{e}-01$ \\
\hline 220 & oxidoreductase aldo/keto reductase family & Vibrio coralliilyticus & ZP_05886239 & $5.38 \mathrm{e}-09$ \\
\hline 292 & aldo/keto reductase & Azorhizobium caulinodans & YP_001527069 & $5.36 \mathrm{e}-01$ \\
\hline 642 & sulfotransferase & Methanocaldococcus vulcanius & ZP_05303437 & $1.87 \mathrm{e}+00$ \\
\hline 220 & hypothetical protein & Bacteroides fragilis & YP_212901 & $5.58 \mathrm{e}-07$ \\
\hline 314 & mobilization (Mob)/recombination (Pre) protein & Listeria monocytogenes & AAA93293 & $7.79 \mathrm{e}+00$ \\
\hline 694 & hypothetical protein CYB_1972 & Synechococcus sp. & YP_478184 & $2.28 \mathrm{e}-05$ \\
\hline 302 & high-affinity zinc transporter periplasmic component & Actinobacillus succinogenes & YP_001345069 & $1.40 \mathrm{e}-01$ \\
\hline
\end{tabular}


Supplementary table 1.

\begin{tabular}{|c|c|c|c|c|c|c|}
\hline NAME & accession number & Lenth & PROTEIN & ORGANIMS & E value & IDENTITY \\
\hline 1_A01 & ZP_03289628 & 647 & hypothetical protein & Clostridium nexile DSM & $2.71 \mathrm{e}-31$ & $96 \%$ \\
\hline 1_A03 & & 203 & No significant similarity found & & & \\
\hline 1_A04 & XP_001274737 & 625 & cytidine and deoxycytidylate deaminase zinc-binding domain protein & Aspergillus clavatus & $1.63 \mathrm{e}-38$ & $57 \%$ \\
\hline 1_A08 & & 445 & No significant similarity found & & & \\
\hline 1_A09 & JQ1541 & 813 & hypothetical $16.9 \mathrm{~K}$ protein & Salmonella typhimurium & $8.72 \mathrm{e}-40$ & $98 \%$ \\
\hline 1_B01 & CAP69667 & 222 & glutaredoxin 1 & Glomus intraradices & $1.84 \mathrm{e}-09$ & $96 \%$ \\
\hline 1_B02 & XP_960148 & 576 & hypothetical protein & Neurospora crassa & $4.41 \mathrm{e}-34$ & $45 \%$ \\
\hline 1_B03 & ACJ54935 & 635 & PBR & Burkholderia cenocepacia & $1.92 \mathrm{e}-18$ & $92 \%$ \\
\hline 1_B07 & XP_001025277 & 357 & hypothetical protein & Tetrahymena thermophila & $4.48 \mathrm{e}+00$ & $35 \%$ \\
\hline 1_B11 & & 498 & No significant similarity found & & & \\
\hline $1 \_\mathrm{C} 02$ & ZP_02071990 & 437 & hypothetical protein & Bacteroides uniformis & $9.91 \mathrm{e}+00$ & $40 \%$ \\
\hline 1_C03 & BAD38920 & 321 & lactate dehydrogenase A & Rhizopus oryzae & $3.13 \mathrm{e}-09$ & $55 \%$ \\
\hline 1_C04 & XP_001772713 & 815 & predicted protein & Physcomitrella patens subsp. patens & $2.38 \mathrm{e}-45$ & $52 \%$ \\
\hline 1_C07 & ACT97501 & 483 & putative transposase & uncultured organism & $1.01 \mathrm{e}-23$ & $96 \%$ \\
\hline 1_C09 & AAX11701 & 858 & chitin deacetylase & Rhizopus stolonifer & $1.31 \mathrm{e}-12$ & $43 \%$ \\
\hline 1_D03 & XP_001014731 & 536 & Protein kinase domain containing protein & Tetrahymena thermophila & $5.62 \mathrm{e}-03$ & $32 \%$ \\
\hline 1_D04 & & 386 & No significant similarity found & & & \\
\hline 1_D07 & XP_002196907 & 178 & Fanconi anemia, complementation group L & Taeniopygia guttata & $9.89 \mathrm{e}+00$ & $25 \%$ \\
\hline 1_D09 & NP_001082494 & 274 & RAD23 homolog B & Xenopus laevis & $1.83 \mathrm{e}-01$ & $48 \%$ \\
\hline 1_D11 & & 320 & No significant similarity found & & & \\
\hline 1_E01 & EDK40915 & 347 & hypothetical protein & Pichia guilliermondii & $1.08 \mathrm{e}-09$ & $80 \%$ \\
\hline 1_E03 & & 308 & No significant similarity found & & & \\
\hline 1_E04 & & 289 & No significant similarity found & & & \\
\hline 1_E05 & & 495 & No significant similarity found & & & \\
\hline 1_E07 & YP_001526574 & 269 & hypothetical protein & Azorhizobium caulinodans & $5.88 \mathrm{e}+00$ & $51 \%$ \\
\hline 1_E09 & & 201 & No significant similarity found & & & \\
\hline 1_E10 & XP_002397490.1 & 376 & hypothetical protein & Moniliophthora perniciosa & $7.19 \mathrm{e}-14$ & $52 \%$ \\
\hline 1_F01 & XP_505403 & 448 & YALI0F14223p & Yarrowia lipolytica & $2.21 \mathrm{e}-23$ & $61 \%$ \\
\hline 1_F03 & EDV08954 & 420 & E3 ubiquitin-protein ligase RSP5 & Saccharomyces cerevisiae & $9.76 \mathrm{e}-11$ & $62 \%$ \\
\hline 1_F08 & & 139 & No significant similarity found & & & \\
\hline 1_F10 & & 308 & No significant similarity found & & & \\
\hline $1 \_\mathrm{G} 01$ & & 405 & No significant similarity found & & & \\
\hline 1_G07 & YP_003118655 & 432 & ATPase associated with various cellular activities AAA_5 & Catenulispora acidiphila & $3.42 \mathrm{e}+00$ & $57 \%$ \\
\hline 1_G09 & & 193 & No significant similarity found & & & \\
\hline 1_G10 & XP_567997 & 557 & ubiquinol-cytochrome $\mathrm{C}$ reductase complex core protein 2 precursor & Cryptococcus neoformans var. neoformans & $4.18 \mathrm{e}-07$ & $46 \%$ \\
\hline 1_H01 & XP_001503071 & 259 & similar to CfOLF3 isoform 1 & Equus caballus & $7.76 \mathrm{e}+00$ & $43 \%$ \\
\hline 1_H02 & & 332 & No significant similarity found & & & \\
\hline
\end{tabular}




\begin{tabular}{|c|c|c|c|c|c|c|}
\hline 1_H09 & EEY22609 & 617 & phenylalanyl-tRNA synthetase beta chain & Verticillium albo-atrum & $6.15 \mathrm{e}-51$ & $69 \%$ \\
\hline 1_H10 & XP_742497 & 373 & hypothetical protein & Plasmodium chabaudi chabaudi & $2.03 e+00$ & $38 \%$ \\
\hline 1_H11 & & 216 & No significant similarity found & & & \\
\hline $102 \mathrm{C}$ & XP_757950 & 525 & hypothetical protein & Ustilago maydis & $1.88 \mathrm{e}+00$ & $56 \%$ \\
\hline $103 \mathrm{C}$ & XP_001831594 & 411 & hypothetical protein & Coprinopsis cinerea okayama & $3.76 \mathrm{e}-07$ & $33 \%$ \\
\hline $106 \mathrm{C}$ & >XP_955949 & 480 & hypothetical protein & Neurospora crassa & $8.63 \mathrm{e}-04$ & $25 \%$ \\
\hline $111 \mathrm{C}$ & XP_001243817 & 818 & hypothetical protein & Coccidioides immitis & $1.62 \mathrm{e}-09$ & $33 \%$ \\
\hline $12 \mathrm{C}$ & XP_759155 & 413 & hypothetical protein & Ustilago maydis & $3.50 \mathrm{e}-29$ & $67 \%$ \\
\hline $1 \mathrm{C}$ & & 381 & No significant similarity found & & & \\
\hline 2_A01 & & 151 & No significant similarity found & & & \\
\hline 2_A02 & & 192 & No significant similarity found & & & \\
\hline 2_A03 & 3IVS-A & 348 & Chain A, Homocitrate Synthase Lys4 & Schizosaccharomyces Pombe & $1.01 \mathrm{e}-15$ & $65 \%$ \\
\hline 2_A05 & XP_002002034 & 674 & GI14236 & Drosophila mojavensis & $4.60 \mathrm{e}+00$ & $29 \%$ \\
\hline 2_A09 & XP_755579 & 208 & acetylornithine aminotransferase & Aspergillus fumigatus & $7.37 \mathrm{e}-03$ & $80 \%$ \\
\hline 2_A10 & XP_002473933 & 279 & predicted protein & Postia placenta & $4.02 \mathrm{e}-01$ & $59 \%$ \\
\hline 2_A11 & XP_001756365 & 124 & predicted protein & Physcomitrella patens subsp. patens & $1.00 \mathrm{e}-15$ & $100 \%$ \\
\hline 2_B03 & & 153 & No significant similarity found & & & \\
\hline 2_B05 & XP_001348635 & 314 & unknown function & Plasmodium falciparum & $9.23 \mathrm{e}-01$ & $27 \%$ \\
\hline 2_B07 & & 153 & No significant similarity found & & & \\
\hline 2_C01 & XP_001933239 & 489 & conserved hypothetical protein & Pyrenophora tritici-repentis & $6.46 \mathrm{e}-23$ & $39 \%$ \\
\hline 2_C03 & XP_002110664 & 372 & alpha tubulin & Trichoplax adhaerens & $4.19 \mathrm{e}-38$ & $93 \%$ \\
\hline 2_C04 & & 152 & No significant similarity found & & & \\
\hline 2_C05 & XP_002623540 & 194 & 60 S ribosomal protein L17 & Ajellomyces dermatitidis & $2.40 \mathrm{e}-17$ & $69 \%$ \\
\hline 2_C07 & XP_001553545 & 515 & hypothetical protein & Botryotinia fuckeliana & $1.00 \mathrm{e}-24$ & $58 \%$ \\
\hline 2_C09 & EEU35087 & 480 & hypothetical protein & Nectria haematococca & $1.29 \mathrm{e}-07$ & $47 \%$ \\
\hline 2_C10 & ACT65758 & 494 & F-ATPase beta subunit & Glomus sp. & $5.75 \mathrm{e}-48$ & $86 \%$ \\
\hline 2_D05 & & 304 & No significant similarity found & & & \\
\hline 2_D07 & XP_776311 & 132 & hypothetical protein & Cryptococcus neoformans var. neoformans & $2.53 \mathrm{e}-03$ & $91 \%$ \\
\hline 2_E01 & XP_001232602 & 572 & similar to GRB2-associated binding protein 1 isoform 1 & Gallus gallus & $3.64 \mathrm{e}-01$ & $28 \%$ \\
\hline 2_E04 & & 299 & No significant similarity found & & & \\
\hline 2_E11 & & 264 & No significant similarity found & & & \\
\hline 2_F02 & & 526 & No significant similarity found & & & \\
\hline 2_F04 & NP_713536 & 412 & glutathione S-transferase & Leptospira interrogans serovar Lai str. 56601 & $1.48 \mathrm{e}-13$ & $58 \%$ \\
\hline 2_F05 & $\mathrm{ABX} 65441$ & 533 & glutathione S-transferase & Chimonanthus praecox & $1.30 \mathrm{e}-20$ & $43 \%$ \\
\hline 2_F07 & CAQ19259 & 151 & Ste12-like transcription factor & Glomus intraradices & $8.01 \mathrm{e}-21$ & $100 \%$ \\
\hline 2_F10 & XP_001096324 & 436 & similar to NmrA-like family domain containing 1 isoform 2 & Macaca mulatta & $4.30 \mathrm{e}-03$ & $55 \%$ \\
\hline 2_G06 & XP_784605 & 211 & similar to LRP16 protein|ref & Strongylocentrotus purpuratus & $5.81 \mathrm{e}-08$ & $55 \%$ \\
\hline 2_G08 & & 286 & No significant similarity found & & & \\
\hline
\end{tabular}




\begin{tabular}{ccccc} 
2_H01 & XP_757156 & 206 & hypothetical protein & Ustilago maydis \\
2_H05 & & 229 & No significant similarity found & 4.09e-65 \\
2_H06 & XP_001888362 & 256 & predicted protein & Laccaria bicolor \\
2_H10 & XP_001877241 & 164 & predicted protein & Laccaria bicolor \\
\hline
\end{tabular}

León-Martínez, D.G. et al.

Phenazine biosynthetic genes of $G$. intraradices

\begin{tabular}{|c|c|c|c|c|c|c|}
\hline $28 \mathrm{C}$ & & 346 & No significant similarity found & & & \\
\hline $2 \mathrm{c}$ & CAF94125 & 610 & unnamed protein product & Tetraodon nigroviridis & $1.95 \mathrm{e}-01$ & $30 \%$ \\
\hline $2 \mathrm{G} 04$ & & 214 & No significant similarity found & & & \\
\hline 3_A01 & XP_002550148 & 448 & conserved hypothetical protein & Candida tropicalis & $1.50 \mathrm{e}-03$ & $43 \%$ \\
\hline 3_A02 & EEQ30863 & 866 & conserved hypothetical protein & Microsporum canis & $1.41 \mathrm{e}-14$ & $25 \%$ \\
\hline 3_A03 & & 199 & No significant similarity found & & & \\
\hline 3_A07 & XP_569615 & 424 & transmembrane protein & Cryptococcus neoformans var. neoformans & $3.33 \mathrm{e}-19$ & $57 \%$ \\
\hline 3_A08 & AAY 62524 & 823 & glutamine synthase & Glomus intraradices & $1.74 \mathrm{e}-51$ & $99 \%$ \\
\hline 3_A09 & & 439 & helix-hairpin-helix DNA-binding motif-containing protein & Methylobacterium sp. & $2.77 \mathrm{e}-02$ & $37 \%$ \\
\hline 3_A10 & XP_368109 & 157 & cytochrome $\mathrm{c}$ subunit $\mathrm{Vb}$, putative & Magnaporthe grisea & $4.38 \mathrm{e}-11$ & $56 \%$ \\
\hline 3_A12 & XP_758506 & 279 & hypothetical protein UM02359.1 & Ustilago maydis & $5.20 \mathrm{e}-33$ & $88 \%$ \\
\hline 3_B02 & XP_001494445 & 495 & similar to methionyl aminopeptidase 2 isoform 2 & Equus caballus & $1.19 \mathrm{e}-45$ & $80 \%$ \\
\hline 3_B08 & XP_001837205 & 672 & hypothetical protein & Coprinopsis cinerea & $3.17 \mathrm{e}-17$ & $59 \%$ \\
\hline 3_B11 & CAX64354 & 327 & unknown function & Plasmodium falciparum & $7.64 \mathrm{e}+00$ & $30 \%$ \\
\hline 3_B12 & XP_001876984 & 749 & predicted protein & Laccaria bicolor & $1.78 \mathrm{e}-09$ & $29 \%$ \\
\hline 3_C01 & & 152 & No significant similarity found & & & \\
\hline 3_C02 & ZP_05886239 & 230 & oxidoreductase aldo/keto reductase family1 & Vibrio coralliilyticus & $2.84 \mathrm{e}-02$ & $61 \%$ \\
\hline 3_C04 & XP_001750808 & 142 & hypothetical protein & Monosiga brevicollis & $2.96 \mathrm{e}-04$ & $73 \%$ \\
\hline 3_C05 & & 163 & No significant similarity found & & & \\
\hline 3_C07 & & 261 & No significant similarity found & & & \\
\hline 3_C09 & A55092 & 150 & catalase & Zea mays & $2.12 \mathrm{e}-05$ & $100 \%$ \\
\hline 3_C10 & ZP_00991846 & 235 & NADH pyrophosphatase & Vibrio splendidus & $2.64 \mathrm{e}+00$ & $41 \%$ \\
\hline 3_C11 & XP_001522405 & 389 & hypothetical protein & Magnaporthe grisea & $1.37 \mathrm{e}-25$ & $52 \%$ \\
\hline 3_C12 & YP_002953232 & 288 & GGDEF domain protein & Desulfovibrio magneticus & $7.77 \mathrm{e}+00$ & $36 \%$ \\
\hline 3_D03 & ABM90641 & 796 & cytochrome $\mathrm{P} 450$ aromatase B & Cynoglossus semilaevis & $4.06 \mathrm{e}-02$ & $21 \%$ \\
\hline 3_D10 & XP_002479808 & 628 & ATP synthase subunit E, putative & Talaromyces stipitatus & $3.24 \mathrm{e}-26$ & $43 \%$ \\
\hline 3_D12 & & 125 & No significant similarity found & & & \\
\hline 3_E03 & XP_002489230 & 356 & hypothetical protein & Sorghum bicolor & $1.07 \mathrm{e}-09$ & $73 \%$ \\
\hline 3_E07 & XP_716749 & 312 & potential NADH-dependent flavin oxidoreductase & Candida albicans & $4.57 \mathrm{e}+00$ & $31 \%$ \\
\hline 3_E09 & XP_001262247 & 206 & elastinolytic metalloproteinase Mep & Neosartorya fischeri & $4.62 \mathrm{e}-13$ & $54 \%$ \\
\hline 3_E10 & & 470 & No significant similarity found & & & \\
\hline 3_E12 & & 114 & No significant similarity found & & & \\
\hline 3_F02 & BAA13797 & 279 & unnamed protein product & Schizosaccharomyces pombe & $1.47 \mathrm{e}-19$ & $83 \%$ \\
\hline 3_F06 & AAN52148 & 308 & $70 \mathrm{kDa}$ heat shock protein 3 & Rhizopus stolonifer & $9.78 \mathrm{e}-40$ & $91 \%$ \\
\hline 3_F07 & & 227 & No significant similarity found & & & \\
\hline 3_F09 & YP_001571636 & 421 & hypothetical protein & Salmonella enterica & $2.03 e+00$ & $41 \%$ \\
\hline
\end{tabular}




\begin{tabular}{|c|c|c|c|c|c|c|}
\hline 3_F10 & AAZ23511 & 297 & cytochrome oxidase subunit II & Aspidiotus nerii & $3.12 \mathrm{e}-01$ & $53 \%$ \\
\hline 3_F11 & & 251 & No significant similarity found & & & \\
\hline 3_G02 & XP_002171726 & 571 & chaperonin-containing T-complex theta subunit Cct8 & Schizosaccharomyces japonicus & $1.29 \mathrm{e}-22$ & $54 \%$ \\
\hline 3 G06 & XP 757093 & 108 & hypothetical protein & Ustilago maydis & $9.18 \mathrm{e}-09$ & $75 \%$ \\
\hline 3_G09 & & 213 & No significant similarity found & & & \\
\hline 3_G11 & CAA23888 & 247 & unnamed protein product & Escherichia coli & $2.20 \mathrm{e}-15$ & \\
\hline
\end{tabular}

León-Martínez, D.G. et al.

Phenazine biosynthetic genes of $G$. intraradices

\begin{tabular}{|c|c|c|c|c|c|c|}
\hline 3_H03 & YP_831133 & 544 & conserved hypothetical protein & Arthrobacter sp. & $2.44 \mathrm{e}-01$ & $41 \%$ \\
\hline 3_H04 & EER18749 & 777 & Tubulin alpha chain, putative & Perkinsus marinus & $5.96 \mathrm{e}-11$ & $100 \%$ \\
\hline 3_H05 & & 297 & No significant similarity found & & & \\
\hline 3_H06 & & 261 & No significant similarity found & & & \\
\hline 3_H07 & XP_001817829 & 283 & hypothetical protein & Aspergillus oryzae & $4.28 \mathrm{e}-06$ & $46 \%$ \\
\hline $39 \mathrm{C}$ & & 289 & No significant similarity found & & & \\
\hline 4_A01 & & 303 & No significant similarity found & & & \\
\hline 4_A03 & & 241 & No significant similarity found & & & \\
\hline 4_A04 & & 291 & No significant similarity found & & & \\
\hline 4_A08 & & 169 & No significant similarity found & & & \\
\hline 4_A10 & & 303 & No significant similarity found & & & \\
\hline 4_B02 & ABQ09367 & 439 & NADH dehydrogenase subunit 3 & Crocodylus siamensis & $8.92 \mathrm{e}-01$ & $24 \%$ \\
\hline 4_B08 & & 136 & No significant similarity found & & & \\
\hline 4_B09 & XP_773060 & 309 & hypothetical protein & Cryptococcus neoformans var. neoformans & $4.56 \mathrm{e}-21$ & $68 \%$ \\
\hline 4_B10 & & 125 & No significant similarity found & & & \\
\hline 4_B11 & NP_001122340 & 488 & Arf GTPase activating protein 10 & Ciona intestinalis & $4.37 \mathrm{e}-03$ & $30 \%$ \\
\hline 4_B12 & & 196 & No significant similarity found & & & \\
\hline 4_C01 & & 119 & No significant similarity found & & & \\
\hline 4_C03 & XP_001785944 & 384 & predicted protein & Physcomitrella patens subsp. patens & $1.34 \mathrm{e}-04$ & $61 \%$ \\
\hline 4_C04 & EDV08774 & 391 & vacuolar protease $\mathrm{B}$ & Saccharomyces cerevisiae & $1.38 \mathrm{e}-01$ & $54 \%$ \\
\hline 4_C08 & XP_002627157 & 322 & zinc metalloprotease & Ajellomyces dermatitidis & $3.71 \mathrm{e}-02$ & $26 \%$ \\
\hline 4_C09 & XP_664835 & 184 & LacOPZ-alpha peptide from pUC9 & Cryptosporidium hominis & $8.08 \mathrm{e}-05$ & $100 \%$ \\
\hline 4_C10 & & 391 & No significant similarity found & & & \\
\hline 4_C11 & XP_663670 & 426 & hypothetical protein & Aspergillus nidulans & $3.00 \mathrm{e}-20$ & $59 \%$ \\
\hline 4_D04 & $>$ ACA30301 & 296 & putative senescence-associated protein & Cupressus sempervirens & $7.38 \mathrm{e}-35$ & $86 \%$ \\
\hline 4_D05 & & 649 & No significant similarity found & & & \\
\hline 4_D10 & XP_451954 & 445 & unnamed protein product & Kluyveromyces lactis & $9.75 \mathrm{e}-03$ & $57 \%$ \\
\hline 4_D11 & & 342 & No significant similarity found & & & \\
\hline 4_DO9 & XP_001247759 & 209 & hypothetical protein & Coccidioides immitis & $5.83 \mathrm{e}-08$ & $45 \%$ \\
\hline 4_E06 & & 481 & No significant similarity found & & & \\
\hline 4_E10 & YP_605634 & 590 & aldo/keto reductase & Deinococcus geothermalis & $1.67 \mathrm{e}-31$ & $64 \%$ \\
\hline 4_E11 & & 387 & No significant similarity found & & & \\
\hline 4_F03 & XP_001910788 & 438 & unnamed protein product & Podospora anserina & $2.26 \mathrm{e}-12$ & $29 \%$ \\
\hline
\end{tabular}




$\begin{array}{lcc}\text { 4_F08 } & & 211 \\ \text { 4_F09 } & & 234 \\ \text { 4_G01 } & \text { XP_001829026 } & 135 \\ \text { 4_G03 } & \text { BAG97315 } & 617 \\ \text { 4_G04 } & \text { XP_001299590 } & 402 \\ \text { 4_G11 } & & 339 \\ \text { 4_H03 } & & 234 \\ \text { 4_H04 } & \text { ZP_04234556 } & 538\end{array}$

No significant similarity found

No significant similarity found

hypothetical protein

unnamed protein product hypothetical protein

$4.31 \mathrm{e}-03$

No significant similarity found

Oryza sativa

$42 \%$

No significant similarity found

Tetracycline resistance protein

Bacillus cereus

$8.92 \mathrm{e}-01$

León-Martínez, D.G. et al.

Phenazine biosynthetic genes of $G$. intraradices

\begin{tabular}{|c|c|c|c|c|c|c|}
\hline 4_H05 & & 169 & No significant similarity found & & & \\
\hline 4_H06 & XP_001829795 & 639 & hypothetical protein & Coprinopsis cinerea & $8.45 e-38$ & $50 \%$ \\
\hline 4_H08 & XP_664835 & 184 & LacOPZ-alpha peptide from pUC9 & Cryptosporidium hominis & $8.08 \mathrm{e}-05$ & $100 \%$ \\
\hline 4_H09 & & 273 & No significant similarity found & & & \\
\hline 4_H11 & ZP_03041609 & 326 & protein of unknown function & Geobacillus sp. & $6.71 \mathrm{e}-04$ & $36 \%$ \\
\hline 4_H12 & & 232 & No significant similarity found & & & \\
\hline $41 \mathrm{C}$ & NP_069807 & 473 & bile acid-inducible operon protein $\mathrm{F}$ (baiF-2) & Archaeoglobus fulgidus & $6.93 \mathrm{e}-01$ & $39 \%$ \\
\hline $42 \mathrm{c}$ & ABK60177 & 285 & putative reverse transcriptase & Zingiber officinale & $4.12 \mathrm{e}-17$ & $100 \%$ \\
\hline $4 \mathrm{C}$ & XP_002473987 & 433 & hypothetical protein & Postia placenta & $6.22 \mathrm{e}-10$ & $30 \%$ \\
\hline $4 \mathrm{H} 02$ & YP_766861 & 528 & putative nitrogen metabolite repression regulator & Rhizobium leguminosarum bv. viciae & $5.57 \mathrm{e}-08$ & $30 \%$ \\
\hline 5_A_01 & & 168 & No significant similarity found & & & \\
\hline 5_A02 & & 101 & No significant similarity found & & & \\
\hline 5_A04 & ZP_05498017 & 262 & arginine biosynthesis bifunctional protein $\mathrm{ArgJ}$ & Clostridium papyrosolvens & $6.74 \mathrm{e}-04$ & $64 \%$ \\
\hline 5_A06 & & 446 & No significant similarity found & & & \\
\hline 5_A12 & & 415 & No significant similarity found & & & \\
\hline 5_B01 & XP_001765628 & 455 & Arl1-family small GTPase & Physcomitrella patens subsp. patens & $8.38 \mathrm{e}-23$ & $59 \%$ \\
\hline 5_B03 & & 161 & No significant similarity found & & & \\
\hline 5_B04 & & 127 & No significant similarity found & & & \\
\hline 5_B06 & ACO05908 & 274 & cAMP dependent protein kinase regulatory subunit & Mucor circinelloides & $4.77 \mathrm{e}-10$ & $53 \%$ \\
\hline 5_B08 & & 201 & No significant similarity found & & & \\
\hline 5_B09 & Q59296 & 173 & Catalase & Campylobacter jejuni & $1.39 \mathrm{e}-09$ & $93 \%$ \\
\hline 5_B11 & ACN10109 & 220 & Ubiquitin & Salmo salar & $1.52 \mathrm{e}-03$ & $91 \%$ \\
\hline 5_C02 & XP_001215724 & 474 & cerevisin precursor & Aspergillus terreus & $3.88 \mathrm{e}-12$ & $67 \%$ \\
\hline 5_C03 & & 275 & No significant similarity found & & & \\
\hline 5_C04 & & 289 & No significant similarity found & & & \\
\hline 5_C06 & XP_001670982 & 777 & Hypothetical protein CBG19959 & Caenorhabditis briggsae & $4.26 \mathrm{e}-09$ & $48 \%$ \\
\hline 5_C07 & EEQ35453 & 578 & $\mathrm{ZZ}$ type zinc finger domain-containing protein & Microsporum canis & $1.43 \mathrm{e}-08$ & $30 \%$ \\
\hline 5_C09 & AAF23219 & 153 & putative long-chain-fatty-acid--CoA ligase & Arabidopsis thaliana & $3.04 \mathrm{e}-12$ & $66 \%$ \\
\hline 5_C10 & XP_001595662 & 437 & hypothetical protein & Sclerotinia sclerotiorum & $1.09 \mathrm{e}-06$ & $60 \%$ \\
\hline 5_C11 & & 538 & No significant similarity found & & & \\
\hline 5_D02 & & 338 & No significant similarity found & & & \\
\hline 5_D04 & & 397 & No significant similarity found & & & \\
\hline
\end{tabular}




$\begin{array}{lcl}\text { 5_D06 } & \text { XP_001633643 } & \text { 595 } \\ \text { 5_D07 } & & 294 \\ \text { 5_E02 } & & 338 \\ \text { 5_E08 } & & 139 \\ \text { 5_E09 } & & 208 \\ \text { 5_F01 } & & 222 \\ \text { 5_F07 } & \text { ABX71761 } & 659 \\ \text { 5_F09 } & \text { XP_001670407 } & 260 \\ \text { 5_G01 } & \text { XP_001731737 } & 368 \\ \text { 5_G02 } & \text { XP 844631 } & 249\end{array}$

No significant similarity found

No significant similarity found

No significant similarity found

glutamine synthetase

Hypothetical protein

hypothetical protein

amino acid transporter 10

$\begin{array}{ccc}\text { Glomus intraradices } & 5.26 \mathrm{e}-56 & 100 \% \\ \text { Caenorhabditis briggsae } & 7.02 \mathrm{e}-01 & 39 \% \\ \text { Malassezia globosa } & 7.30 \mathrm{e}-03 & 78 \% \\ \text { Trypanosoma brucei } & 4.43 \mathrm{e}+00 & 40 \%\end{array}$

León-Martínez, D.G. et al.

Phenazine biosynthetic genes of $G$. intraradices

\begin{tabular}{|c|c|c|c|c|c|c|}
\hline 5_G03 & XP_786368 & 393 & similar to beclin 1 & Strongylocentrotus purpuratus & $2.12 \mathrm{e}-05$ & $52 \%$ \\
\hline 5_G07 & & 156 & No significant similarity found & & & \\
\hline 5_G08 & XP_002396446 & 130 & hypothetical protein & Moniliophthora perniciosa & $6.24 \mathrm{e}-10$ & $65 \%$ \\
\hline 5_G11 & YP_001304493 & 335 & hypothetical protein & Parabacteroides distasonis & $6.89 \mathrm{e}-01$ & $32 \%$ \\
\hline 5_H01 & & 336 & No significant similarity found & & & \\
\hline 5_H02 & & 204 & No significant similarity found & & & \\
\hline 5_H03 & & 354 & No significant similarity found & & & \\
\hline 5_H05 & XP_001877132 & 181 & predicted protein & Laccaria bicolor & $2.97 \mathrm{e}-15$ & $69 \%$ \\
\hline 5_H06 & XP_001229682 & 718 & hypothetical protein & Chaetomium globosum & $4.42 \mathrm{e}-31$ & $47 \%$ \\
\hline 5_H07 & XP_001023614 & 296 & hypothetical protein & Tetrahymena thermophila & $4.52 \mathrm{e}+00$ & $44 \%$ \\
\hline 5_H09 & & 136 & No significant similarity found & & & \\
\hline $56 \mathrm{c}$ & AAD37832 & 433 & metallothionein-like protein & Jasus edwardsii & $4.77 \mathrm{e}-02$ & $27 \%$ \\
\hline $57 \mathrm{C}$ & XP_001910694 & 467 & unnamed protein product & Podospora anserina & $4.23 \mathrm{e}-06$ & $53 \%$ \\
\hline 6_D01 & & 124 & No significant similarity found & & & \\
\hline 6_A01 & & 214 & No significant similarity found & & & \\
\hline 6_A02 & & 253 & No significant similarity found & & & \\
\hline 6_A04 & & 500 & No significant similarity found & & & \\
\hline 6_A05 & & 596 & No significant similarity found & & & \\
\hline 6_A08 & & 290 & No significant similarity found & & & \\
\hline 6_A09 & & 124 & No significant similarity found & & & \\
\hline 6_A10 & & 237 & No significant similarity found & & & \\
\hline 6_B01 & & 160 & No significant similarity found & & & \\
\hline 6_B03 & EEQ29167 & 565 & hscarg protein & Microsporum canis & $1.43 \mathrm{e}-02$ & $43 \%$ \\
\hline 6_B05 & XP_772638 & 499 & hypothetical protein & Cryptococcus neoformans var. neoformans & $4.14 \mathrm{e}-01$ & $42 \%$ \\
\hline 6_B11 & YP_015994 & 337 & F0F1 ATP synthase subunit alpha & Mycoplasma mobile & $9.91 \mathrm{e}+00$ & $36 \%$ \\
\hline 6_C06 & & 247 & No significant similarity found & & & \\
\hline 6_C07 & & 169 & No significant similarity found & & & \\
\hline 6_C12 & & 404 & No significant similarity found & & & \\
\hline 6_D05 & & 249 & No significant similarity found & & & \\
\hline
\end{tabular}




$\begin{array}{lcc}\text { 6_D06 } & & 258 \\ \text { 6_D08 } & \text { XP_001663040 } & 457 \\ \text { 6_D09 } & \text { XP_001835135 } & 572 \\ \text { 6_D11 } & \text { XP_757560 } & 105 \\ \text { 6_E01 } & & 273 \\ \text { 6_E06 } & & 120 \\ \text { 6_E07 } & \text { XP_001384486 } & 425 \\ \text { 6_F02 } & \text { XP_002593599 } & 332 \\ \text { 6_F04 } & & 498 \\ \text { 6_F05 } & & 152 \\ \text { 6_F07 } & \text { XP_759316 } & 299 \\ \text { 6_F09 } & \text { YP_046169 } & 230\end{array}$

No significant similarity found hypothetical protein

40S ribosomal protein $\mathrm{S} 14$

hypothetical protein

No significant similarity found

No significant similarity found

hypothetical protein

hypothetical protein

No significant similarity found

No significant similarity found hypothetical protein

$\begin{array}{ccc}\text { Aedes aegypti } & 1.13 \mathrm{e}-03 & 30 \% \\ \text { Coprinopsis cinerea } & 8.30 \mathrm{e}-46, & 76 \% \\ \text { Ustilago maydis } & 7.07 \mathrm{e}-09 & 82 \% \\ & & \\ & & \\ \text { Pichia stipitis } & 2.64 \mathrm{e}-16 & 41 \% \\ \text { Branchiostoma floridae } & 2.78 \mathrm{e}-26 & 92 \% \\ & & \\ & & \\ \text { Ustilago maydis } & 4.48 \mathrm{e}-16 & 68 \% \\ \text { Acinetobacter sp. } & 2.65 \mathrm{e}+00 & 40 \%\end{array}$

León-Martínez, D.G. et al.

Phenazine biosynthetic genes of $G$. intraradices

\begin{tabular}{|c|c|c|c|c|c|c|}
\hline 6_G01 & XP_001588748 & 385 & hypothetical protein & Sclerotinia sclerotiorum & $3.90 \mathrm{e}-12$ & $45 \%$ \\
\hline 6_G03 & & 252 & No significant similarity found & & & \\
\hline 6_G10 & & 136 & No significant similarity found & & & \\
\hline 6_H02 & & 249 & No significant similarity found & & & \\
\hline 6_H06 & XP_001833710 & 497 & hypothetical protein & Coprinopsis cinerea & $2.26 \mathrm{e}-44$ & $84 \%$ \\
\hline 6_H07 & AAD00455 & 135 & heat shock protein 70 & Pneumocystis carinii f. sp. carinii & $2.21 \mathrm{e}-07$ & $72 \%$ \\
\hline 6_H08 & XP_001215073 & 144 & phosphoenolpyruvate carboxykinase & Aspergillus terreus & $4.91 \mathrm{e}-02$ & $83 \%$ \\
\hline 6_H09 & & 273 & No significant similarity found & & & \\
\hline 6_H12 & EEH16996 & 430 & ketol-acid reductoisomerase & Paracoccidioides brasiliensis & $5.39 \mathrm{e}-46$ & $68 \%$ \\
\hline $62 \mathrm{c}$ & P20015 & 459 & Full=Proteinase T; Flags: Precursor & & $9.78 \mathrm{e}-32$ & $53 \%$ \\
\hline $63 \mathrm{C}$ & XP_001261930 & 225 & AMP deaminase, putative & Neosartorya fischeri & $7.77 \mathrm{e}+00$ & $51 \%$ \\
\hline 7_A02 & & 198 & No significant similarity found & & & \\
\hline 7_A04 & XP_571997 & 275 & bud site selection-related protein & Cryptococcus neoformans var. neoformans & $2.87 \mathrm{e}-15$ & $63 \%$ \\
\hline 7_A07 & & 147 & No significant similarity found & & & \\
\hline 7_A09 & & 136 & No significant similarity found & & & \\
\hline 7_A11 & AAR11779 & 129 & cyclophilin A & Chlamys farreri & $8.13 \mathrm{e}-18$ & $95 \%$ \\
\hline 7_A12 & АCT 82769 & 181 & polyubiquitin & Nicotiana tabacum & $2.51 \mathrm{e}-06$ & $96 \%$ \\
\hline 7_B03 & ZP_05091409 & 720 & hypothetical protein & Carboxydibrachium pacificum & $4.07 \mathrm{e}+00$ & $34 \%$ \\
\hline 7_B05 & ZP_03396463 & 686 & hypothetical protein & Pseudomonas syringae pv. tomato & $4.80 \mathrm{e}+00$ & $27 \%$ \\
\hline 7_B07 & XP_001989813 & 160 & GH18591 & Drosophila grimshawi & $1.41 \mathrm{e}-01$ & $36 \%$ \\
\hline 7_B08 & & 138 & No significant similarity found & & & \\
\hline 7_B09 & & 112 & No significant similarity found & & & \\
\hline 7_B10 & & 161 & No significant similarity found & & & \\
\hline 7_C01 & XP_001832262 & 291 & hypothetical protein & Coprinopsis cinerea & $5.73 \mathrm{e}-03$ & $66 \%$ \\
\hline 7_C06 & & 134 & No significant similarity found & & & \\
\hline 7_C07 & ABX52130 & 434 & olfactory receptor 604 (predicted) & Papio anubis & $4.47 \mathrm{e}+00$ & $37 \%$ \\
\hline 7_C11 & & 197 & No significant similarity found & & & \\
\hline
\end{tabular}




$\begin{array}{lcl}\text { 7_D01 } & \text { AAM90675 } & 767 \\ \text { 7_D03 } & & 239 \\ \text { 7_D04 } & \text { XP_001381397 } & 124 \\ \text { 7_D05 } & \text { XP_001912404 } & 262 \\ \text { 7_D08 } & \text { XP_680306 } & 203 \\ \text { 7_D11 } & & 369 \\ \text { 7_E01 } & & 222 \\ \text { 7_E03 } & \text { XP_002430829 } & 277 \\ \text { 7_E04 } & \text { XP_001834700 } & 401 \\ \text { 7_E05 } & \text { XP_001263957 } & 598 \\ \text { 7_E07 } & & 245 \\ \text { 7_E08 } & \text { XP_001223491 } & 561 \\ \text { 7_E09 } & & 387 \\ \text { 7_E10 } & \text { XP_676548 } & 225\end{array}$

heat shock protein Hsp90

No significant similarity found

similar to Napsin A aspartic peptidase, partial

unnamed protein product |emb|CAP59885.1

$$
\text { hypothetical protein }
$$

No significant similarity found

No significant similarity found

cabrous protein, putative

predicted protein

mating-type protein MAT1-2

No significant similarity found

hypothetical protein

No significant similarity found

hypothetical protein

$\begin{array}{ccc}\text { Achlya ambisexualis } & 1.33 \mathrm{e}-63 & 57 \% \\ & & \\ \text { Monodelphis domestica } & 4.65 \mathrm{e}-13 & 80 \% \\ \text { Podospora anserina } & 4.10 \mathrm{e}-01 & 60 \% \\ \text { Plasmodium berghei } & 7.68 \mathrm{e}+00 & 35 \% \\ & & \\ & & \\ \text { Codiculus humanus corporis } & 4.46 \mathrm{e}+00, & 36 \% \\ \text { Coprinopsis cinerea } & 9.75 \mathrm{e}-03 & 51 \% \\ \text { Neosartorya fischeri } & 4.54 \mathrm{e}+00 & 46 \% \\ & & \\ \text { Chaetomium globosum } & 8.85 \mathrm{e}-02 & 30 \% \\ & & \\ \text { Plasmodium berghei } & 5.95 \mathrm{e}+00 & 38 \%\end{array}$

Phenazine biosynthetic genes of $G$. intraradices

León-Martínez, D.G. et al.

\begin{tabular}{|c|c|c|c|c|c|c|}
\hline 7_E11 & XP_002585310 & 279 & predicted protein & Uncinocarpus reesii & $2.20 \mathrm{e}-07$ & $42 \%$ \\
\hline 7_F03 & & 155 & No significant similarity found & & & \\
\hline 7_F04 & XP_001321831 & 485 & hypothetical protein & Trichomonas vaginalis & $1.56 \mathrm{e}+00$ & $29 \%$ \\
\hline 7_F10 & AAU43212 & 687 & actin & Phalansterium solitarium & $7.22 \mathrm{e}-04$ & $96 \%$ \\
\hline 7_F11 & XP_001983483 & 266 & GH15554 & Drosophila grimshawi & $7.71 \mathrm{e}+00$ & $30 \%$ \\
\hline 7_F12 & EEY18608 & 786 & $\mathrm{C} 2 \mathrm{H} 2$ finger domain containing protein $\mathrm{FlbC}$ & Verticillium albo-atrum & $4.98 \mathrm{e}-21$ & $72 \%$ \\
\hline 7_G01 & XP_001822192 & 423 & hypothetical protein & Aspergillus oryzae & 3.69e-10, & $47 \%$ \\
\hline 7_G03 & YP_002720507 & 560 & hypothetical hypothetical protein & Brachyspira hyodysenteriae & $2.04 \mathrm{e}-01$ & $33 \%$ \\
\hline 7_G04 & XP_367364 & 517 & glycogen synthase & Magnaporthe grisea & $7.83 \mathrm{e}-25$ & $51 \%$ \\
\hline 7_G05 & & 201 & No significant similarity found & & & \\
\hline 7_G06 & NP_001016124 & 209 & interferon-related developmental regulator 1 & Xenopus (Silurana) tropicalis & $3.31 \mathrm{e}-03$ & $34 \%$ \\
\hline 7_G07 & XP_002542314 & 242 & calcium/calmodulin-dependent protein kinase & Uncinocarpus reesii & $7.62 \mathrm{e}-08$ & $57 \%$ \\
\hline 7_G10 & XP_002155447 & 672 & similar to zonadhesin & Hydra magnipapillata & $4.42 \mathrm{e}-19$ & $52 \%$ \\
\hline 7_H06 & XP_001637380 & 577 & predicted protein & Nematostella vectensis & $1.21 \mathrm{e}-15$ & $65 \%$ \\
\hline 7_H12 & XP_001729946 & 684 & hypothetical protein MGL_2932 & Malassezia globosa & $1.56 \mathrm{e}-03$ & $53 \%$ \\
\hline 75 & NP_730591 & 845 & skuld, isoform E & Drosophila melanogaster & $1.44 \mathrm{e}+00$ & $27 \%$ \\
\hline $77 \mathrm{C}$ & XP_001829157 & 338 & predicted protein $\mathrm{lk}$ & Coprinopsis cinerea & $2.43 e-14$ & $50 \%$ \\
\hline 8_A02 & & 373 & No significant similarity found & & & \\
\hline 8_A03 & Q59296 & 173 & Catalase & Campylobacter jejuni & $1.39 \mathrm{e}-09$ & $93 \%$ \\
\hline 8_A06 & XP_002611728 & 407 & hypothetical protein & Branchiostoma floridae & $2.36 \mathrm{e}-25$ & $53 \%$ \\
\hline 8_A08 & XP_970073 & 456 & similar to serine/threonine protein kinase & Tribolium castaneum & $4.45 \mathrm{e}+00$ & $34 \%$ \\
\hline 8_A09 & & 156 & No significant similarity found & & & \\
\hline 8_A11 & & 330 & No significant similarity found & & & \\
\hline 8_B01 & & 222 & No significant similarity found & & & \\
\hline 8_B05 & EEU38190 & 184 & hypothetical protein & Nectria haematococca & $1.68 \mathrm{e}-02$ & $39 \%$ \\
\hline
\end{tabular}




\begin{tabular}{|c|c|c|c|c|c|c|}
\hline 8_B07 & & 305 & No significant similarity found & & & \\
\hline 8_B08 & & 321 & No significant similarity found & & & \\
\hline 8_B10 & & 395 & No significant similarity found & & & \\
\hline 8_B11 & & 245 & No significant similarity found & & & \\
\hline 8_C03 & XP_002047433 & 338 & GJ13437 & Drosophila virilis & $4.45 \mathrm{e}+00$ & $36 \%$ \\
\hline 8_C07 & XP_001428970 & 620 & hypothetical protein & Paramecium tetraurelia & $1.72 \mathrm{e}+00$ & $29 \%$ \\
\hline 8_C10 & & 430 & No significant similarity found & & & \\
\hline 8_C12 & ZP_02612185 & 301 & putative membrane protein & Clostridium botulinum & $7.66 e+00$ & $32 \%$ \\
\hline 8_D01 & & 298 & No significant similarity found & & & \\
\hline 8_D02 & XP_002158150 & 811 & similar to uncharacterized hypothalamus protein HT010, partial & Hydra magnipapillata & $2.47 \mathrm{e}-02$ & $30 \%$ \\
\hline 8_D06 & XP_001878372 & 842 & predicted protein & Laccaria bicolor & $1.75 \mathrm{e}-43$ & $68 \%$ \\
\hline 8_D08 & $>$ XP_759384 & 263 & $40 \mathrm{~S}$ ribosomal protein $\mathrm{S} 20$ & Ustilago maydis & $1.35 \mathrm{e}-12$ & $70 \%$ \\
\hline 8_D09 & XP_570849 & 202 & endopeptidase & Cryptococcus neoformans var. neoformans & $1.76 \mathrm{e}-20$ & $94 \%$ \\
\hline 8_D10 & & 123 & No significant similarity found & & & \\
\hline 8_E_04 & XP_002283214 & 527 & glutathione S-transferase 3 & Vitis vinifera & $1.64 \mathrm{e}-20$ & $41 \%$ \\
\hline 8_E05 & AAN35142 & 189 & alpha-tubulin & Nowakowskiella elegans & $9.17 \mathrm{e}-09$ & $100 \%$ \\
\hline
\end{tabular}

León-Martínez, D.G. et al.

Phenazine biosynthetic genes of $G$. intraradices

\begin{tabular}{|c|c|c|c|c|c|c|}
\hline 8_E06 & & 241 & No significant similarity found & & & \\
\hline 8_E12 & & 201 & No significant similarity found & & & \\
\hline 8_F07 & XP_001945715 & 647 & similar to Glycerol-3-phosphate dehydrogenase & Acyrthosiphon pisum & $1.34 \mathrm{e}-56$ & $82 \%$ \\
\hline 8_F08 & ABM92196 & 387 & tubulin, alpha 3 & synthetic construct & $4.12 \mathrm{e}-38$ & $92 \%$ \\
\hline 8_F09 & CAR65717 & 236 & DEHA2D19008p & Debaryomyces hansenii & $5.89 \mathrm{e}+00$ & $33 \%$ \\
\hline 8_F10 & & 380 & No significant similarity found & & & \\
\hline 8_F12 & & 389 & No significant similarity found & & & \\
\hline 8_G07 & ZP_01730719 & 536 & hypothetical protein CY0110_06274 & Cyanothece sp. & $4.66 \mathrm{e}-20$ & $56 \%$ \\
\hline 8_G08 & YP_002355004 & 248 & Glutathione S-transferase domain protein & Thauera sp. & $5.98 \mathrm{e}-13$ & $66 \%$ \\
\hline 8_H02 & XP_001877094 & 413 & predicted protein & Laccaria bicolor & $1.43 \mathrm{e}-14$ & $40 \%$ \\
\hline 8_H04 & & 129 & No significant similarity found & & & \\
\hline 8_H09 & XP_001525198 & 272 & hexokinase & Lodderomyces elongisporus & $5.85 \mathrm{e}-08$ & $40 \%$ \\
\hline 8_H11 & XP_745554 & 477 & hypothetical protein & Plasmodium chabaudi chabaudi & $8.97 \mathrm{e}-01$ & $38 \%$ \\
\hline $88 \mathrm{C}$ & XP_001008343 & 553 & hypothetical protein & Tetrahymena thermophila & $1.67 \mathrm{e}+00$ & $45 \%$ \\
\hline $89 \mathrm{C}$ & XP_001879447 & 473 & predicted protein & Laccaria bicolor & $5.66 \mathrm{e}-11$ & $34 \%$ \\
\hline 9_E03 & XP_385327 & 615 & hypothetical protein & Gibberella zeae & $2.14 \mathrm{e}-03$ & $31 \%$ \\
\hline 9_A09 & XP_001728741 & 576 & hypothetical protein & Malassezia globosa & $9.19 \mathrm{e}-24$ & $68 \%$ \\
\hline 9_B05 & NP_595707 & 213 & transcription factor Atf21 & Schizosaccharomyces pombe & $5.07 \mathrm{e}-04$ & $42 \%$ \\
\hline 9_B09 & & 102 & No significant similarity found & & & \\
\hline 9_B11 & ABB90955 & 420 & elongation factor 1-alpha & Glomus intraradices & $9.98 \mathrm{e}-48$ & $99 \%$ \\
\hline $9+\mathrm{C} 01$ & & 266 & No significant similarity found & & & \\
\hline 9_C06 & ACU18400 & 153 & unknown & Glycine max & $6.36 \mathrm{e}-02$ & $56 \%$ \\
\hline 9_C09 & XP_761073 & 446 & hypothetical protein & Ustilago maydis & $3.34 \mathrm{e}-11$ & $58 \%$ \\
\hline
\end{tabular}




$\begin{array}{lcl}\text { 9_D01 } & \text { NP_001116984 } & 460 \\ \text { 9_D03 } & \text { XP_682393 } & 169 \\ \text { 9_D06 } & & 229 \\ \text { 9_E01 } & \text { CAB88663 } & 259 \\ \text { 9_E07 } & & 162 \\ \text { 9_E09 } & \text { XP_801913 } & 468 \\ \text { 9_F05 } & \text { XP_002565512 } & 450 \\ \text { 9_F06 } & & 292 \\ \text { 9_F09 } & \text { ZP_04047349 } & 297 \\ \text { 9_G03 } & \text { NP_001076115 } & 372 \\ \text { 9_G05 } & & 292 \\ \text { 9_G08 } & \text { EDP56321 } & 247 \\ \text { 9_G09 } & \text { XP_002152882 } & 266 \\ \text { 9_G10 } & \text { XP_001771315 } & 288 \\ \text { 9_G12 } & \text { XP_002475016 } & 324 \\ \text { 9_H04 } & \text { XP_002416916 } & 292 \\ \text { 9_H07 } & \text { XP_001877844 } & 489 \\ \text { 9_H09 } & & 328\end{array}$

rab11 GTPase homolog SUrab11p hypothetical protein

No significant similarity found

argininosuccinate lyase

No significant similarity found

hypothetical protein isoform 2

$$
\text { Pc22g15960 }
$$

No significant similarity found

predicted oxidoreductase similar to aryl-alcohol dehydrogenase

inter-alpha (globulin) inhibitor $\mathrm{H} 1$

No significant similarity found

P-type calcium ATPase, putative

RING finger protein, putative

predicted protein

predicted protein

homoserine dehydrogenase

glyoxal oxidasegb

No significant similarity found

$\begin{array}{ccc}\begin{array}{c}\text { Strongylocentrotus purpuratus } \\ \text { Aspergillus nidulans }\end{array} & 7.00 \mathrm{e}-38 & 90 \% \\ & 1,07 \mathrm{E}-01 & 85 \% \\ \text { Agaricus bisporus } & 3.14 \mathrm{e}-08 & 81 \% \\ & & \\ \text { Strongylocentrotus purpuratus } & 3.55 \mathrm{e}-21 & 44 \% \\ \text { Penicillium chrysogenum } & 2.30 \mathrm{e}-04, & 51 \% \\ & & \\ \text { Brachyspira murdochii } & 3.00 \mathrm{e}-04 & 52 \% \\ \text { Oryctolagus cuniculus } & 2.41 \mathrm{e}-01, & 44 \% \\ & & \\ \text { Aspergillus fumigatus } & 7.55 \mathrm{e}-16, & 54 \% \\ \text { Penicillium marneffei } & 4.99 \mathrm{e}-07, & 38 \% \\ \text { Physcomitrella patens subsp. patens } & 1,66 \mathrm{E}-18 & 78 \% \\ \quad \text { Postia placenta } & 3.45 \mathrm{e}-08 & 48 \% \\ \text { Candida dubliniensis } & 5.04 \mathrm{e}-23 & 62 \% \\ \text { Laccaria bicolor } & 6.29 \mathrm{e}-02 & 33 \% \\ \quad & & \end{array}$

Phenazine biosynthetic genes of $G$. intraradices

León-Martínez, D.G. et al. 328

\begin{tabular}{|c|c|c|c|c|c|c|}
\hline $98 \mathrm{C}$ & XP_001592989 & 500 & hypothetical protein & Sclerotinia sclerotiorum & $1.42 \mathrm{e}-01$ & $58 \%$ \\
\hline $9 \mathrm{C}$ & EEQ83856 & 210 & hemolysin-III channel protein Izh2 & Ajellomyces dermatitidis & 1.33e-12, & $62 \%$ \\
\hline c_1 & & 255 & No significant similarity found & & & \\
\hline c_10 & & 150 & No significant similarity found & & & \\
\hline c_11 & & 307 & No significant similarity found & & & \\
\hline c_12 & XP_001645325 & 715 & hypothetical protein & Vanderwaltozyma polyspora & $2.76 \mathrm{e}-09$ & $27 \%$ \\
\hline c_13 & YP_740739 & 287 & heme maturase & Tetrahymena malaccensis & $7.80 \mathrm{e}+00$ & $33 \%$ \\
\hline c_14 & & 741 & No significant similarity found & & & \\
\hline c_15 & & 120 & No significant similarity found & & & \\
\hline c_16 & & 159 & No significant similarity found & & & \\
\hline c_17 & & 138 & No significant similarity found & & & \\
\hline c_18 & ACJ04669 & 458 & glycoprotein & Iris yellow spot virus & $5.79 \mathrm{e}+00$ & $70 \%$ \\
\hline c_19 & XP_757513 & 545 & hypothetical protein UM01366.1 & Ustilago maydis & $3.70 \mathrm{e}-66$ & $92 \%$ \\
\hline c_2 & XP_001729651 & 487 & hypothetical protein & Malassezia globosa & $1.73 \mathrm{e}-28$ & $51 \%$ \\
\hline c_20 & & 196 & No significant similarity found & & & \\
\hline c_21 & XP_001386405 & 588 & hypothetical protein & Pichia stipitis & $5.17 \mathrm{e}-07$ & $31 \%$ \\
\hline c_22 & & 201 & No significant similarity found & & & \\
\hline c_23 & AAW82439 & 508 & guanine nucleotide binding protein beta subunit & Thanatephorus cucumeris & $2.40 \mathrm{e}-63$ & $81 \%$ \\
\hline c_24 & & 249 & No significant similarity found & & & \\
\hline c_25 & ZP_00143234 & 515 & hypothetical protein & Fusobacterium nucleatum subsp. vincentii & $1.35 \mathrm{e}+00$ & $32 \%$ \\
\hline c_26 & NP_000773 & 339 & cytochrome P450 family 24 subfamily A polypeptide 1 isoform 1 precursor & Homo sapiens & $1.52 \mathrm{e}+00$ & $33 \%$ \\
\hline
\end{tabular}




$\begin{array}{ccc}\text { c_27 } & & 274 \\ \text { c_28 } & & 191 \\ \text { c_29 } & \text { XP_002499194 } & 147 \\ \text { c_3 } & \text { YP_1527069 } & 292 \\ \text { c_30 } & \text { NP_690845 } & 299 \\ \text { c_31 } & \text { XP_001544351 } & 207 \\ \text { c_32 } & & 190 \\ \text { c_33 } & \text { XP_002031750 } & 691 \\ \text { c_34 } & & 304 \\ \text { c_36 } & \text { XP_001765643 } & 533 \\ \text { c_37 } & \text { XP_002618663 } & 464 \\ \text { c_39 } & \text { XP_001371508 } & 238 \\ \text { c_4 } & & 224 \\ \text { c_40 } & \text { XP_002004468 } & 477 \\ \text { c_41 } & \text { XP_780136 } & 286 \\ \text { c_42 } & \text { XP_001606326 } & 683 \\ \text { c_43 } & & 294 \\ \text { c_44 } & \text { XP_002045681 } & 423 \\ \text { c_45 } & & 467 \\ \text { c_46 } & & 449\end{array}$

No significant similarity found

No significant similarity found

ZYRO0E06248p |emb|CAR30939.1| ZYRO0E06248p aldo/keto reductase

Mitochondrial protein of unknown function

heat shock $70 \mathrm{kDa}$ protein 7

No significant similarity found

$$
\text { GM26172 }
$$

No significant similarity found

$$
\text { predicted protein }
$$

predicted protein

hypothetical protein

No significant similarity found

$$
\text { GI19951 }
$$

similar to Im:7148063 protein

similar to GA19427-PA

No significant similarity found

$$
\text { GM16395 }
$$

No significant similarity found

No significant similarity found

$\begin{array}{ccc}\text { Zygosaccharomyces rouxii } & 8.63 \mathrm{e}-07 & 65 \% \\ \text { Azorhizobium caulinodans } & 5.36 \mathrm{e}-01 & 40 \% \\ \text { Saccharomyces cerevisiae } & 1.40 \mathrm{e}-01 & 50 \% \\ \text { Ajellomyces capsulatus } & 3.10 \mathrm{e}-01 & 92 \% \\ & & \\ & 3.75 \mathrm{e}+00, & 30 \% \\ \text { Drosophila sechellia } & & \\ & 2.38 \mathrm{e}-22, & 41 \% \\ \text { hyscomitrella patens subsp. patens } & 5.65 \mathrm{e}+00 & 50 \% \\ \text { Clavispora lusitaniae } & 1.39 \mathrm{e}-09 & 84 \% \\ \text { Monodelphis domestica } & & \\ & 7.59 \mathrm{e}+00 & 35 \% \\ \text { Drosophila mojavensis } & 9.18 \mathrm{e}-01 & 56 \% \\ \text { Strongylocentrotus purpuratus } & 6.17 \mathrm{e}+00 & 45 \% \\ \quad \text { Nasonia vitripennis } & & \\ & 1.39 \mathrm{e}-33 & 97 \% \\ \text { Drosophila sechellia } & & \end{array}$

León-Martínez, D.G. et al.

Phenazine biosynthetic genes of $G$. intraradices

\begin{tabular}{ccc}
\hline c_47 & & 502 \\
c_48 & & 161 \\
c_49 & ACT78499 & 537 \\
c_5 & ZP_05303437 & 642 \\
c_50 & & 146 \\
c_51 & YP_212901 & 220 \\
c_52 & EEQ28156 & 177 \\
c_53 & & 176 \\
c_54 & XP_001799670 & 372 \\
c_55 & XP_759979 & 343 \\
c_56 & XP_001470964 & 643 \\
c_57 & & 257 \\
c_58 & XP_759578 & 260 \\
c_59 & XP_001731772 & 228 \\
c_6 & & 651 \\
c_60 & & 212 \\
c_61 & & 209 \\
c_62 & AAA93293 & 314
\end{tabular}

No significant similarity found

No significant similarity found

cysteine/serine protease

sulfotransferase

No significant similarity found

hypothetical protein

alpha-centractin

No significant similarity found

hypothetical protein SNOG_09375

hypothetical protein UM03832.1

conserved hypothetical protein

No significant similarity found

hypothetical protein UM03431.

hypothetical protein

No significant similarity found

No significant similarity found

No significant similarity found

mobilization (Mob)/recombination (Pre) protein
Porcine reproductive and respiratory syndrome virus

$9.87 \mathrm{e}+00$

$1.87 \mathrm{e}+00 \quad 29 \%$

Methanocaldococcus vulcanius

$5.58 \mathrm{e}-07 \quad 55 \%$

Bacteroides fragilis

$4.01 \mathrm{e}-09-79 \%$

Phaeosphaeria nodorum

Ustilago maydis

$2.65 \mathrm{e}-16$

$4.55 \mathrm{e}+00$

Tetrahymena thermophila

$3.59 \mathrm{e}-13$

$2.65 \mathrm{e}-16$

$55 \%$

Ustilago maydis

$98 \%$

Listeria monocytogenes

$7.79 \mathrm{e}+00$,

$30 \%$ 


$\begin{array}{ccc}\text { c_63 } & \text { XP_002547626 } & 300 \\ \text { c_64 } & \text { XP_002374655 } & 452 \\ \text { c_65 } & \text { YP_001345069 } & 302 \\ \text { c_66 } & & 456 \\ \text { c_67 } & \text { XP_001881146 } & 187 \\ \text { c_68 } & \text { XP_774968 } & 212 \\ \text { c_69 } & & 547 \\ \text { c_7 } & & 397 \\ \text { c_70 } & \text { YP_155013 } & 498 \\ \text { c_71 } & & 136 \\ \text { c_72 } & & 170 \\ \text { c_73 } & \text { ABJ98722 } & 172 \\ \text { c_74 } & & 136 \\ \text { c_75 } & \text { ACM89242 } & 102 \\ \text { c_76 } & & 173 \\ \text { c_77 } & & 195 \\ \text { c_78 } & & 166 \\ \text { c_79 } & & 143 \\ \text { c_8 } & \text { XP_758864 } & 703 \\ \text { c_80 } & & 468 \\ \text { c_81 } & \text { XP_570002 } & 355 \\ \text { c_82 } & \text { YP_003005810 } & 811\end{array}$

León-Martínez, D.G. et al. hypothetical protein CTRG 01933

CP2 transcription factor, putative

high-affinity zinc transporter periplasmic component

No significant similarity found eu2.Lbscf0012g03030

hypothetical protein CNBF1320

No significant similarity found

No significant similarity found

glutathione S-transferase-like protein

No significant similarity found

No significant similarity found

heat shock protein 71

No significant similarity found histone $\mathrm{H} 3 \mathrm{~A}$

No significant similarity found

No significant similarity found

No significant similarity found

No significant similarity found

hypothetical protein UM02717.1

No significant similarity found

hypothetical protein

Glutathione transferase

$\begin{array}{ccc}\text { Candida tropicalis } & 3.77 \mathrm{e}-15, & 52 \% \\ \text { Aspergillus flavus } & 1.26 \mathrm{e}-10 & 37 \% \\ \text { Actinobacillus succinogenes } & 1.40 \mathrm{e}-01 & 30 \% \\ \text { Laccaria bicolor } & 1.09 \mathrm{e}-01 & 72 \% \\ \text { Cryptococcus neoformans var. neoformans } & 1.10 \mathrm{e}-06 & 48 \% \\ \text { Idiomarina loihiensis } & & \\ & 4.57 \mathrm{e}-08 & 44 \% \\ \text { Perna viridis } & & \\ \text { Meta ovalis } & 3.08 \mathrm{e}-17, & 96 \% \\ & 6.83 \mathrm{e}-12 & 100 \% \\ & & \\ & & \\ \text { Ustilago maydis } & & 68 \% \\ & & \\ \text { Dickeya zeae } & & \\ \text { Cryptococcus neoformans var. neoformans } & 4.45 \mathrm{e}-24 & \end{array}$

\begin{tabular}{|c|c|c|c|c|c|c|}
\hline c_83 & XP_002514260 & 302 & Galactose oxidase precursor, putative & Ricinus communis & $6.92 \mathrm{e}-01$ & $41 \%$ \\
\hline c_84 & & 138 & No significant similarity found & & & \\
\hline c_85 & YP_478184 & 694 & hypothetical protein & Synechococcus sp. & $2.28 \mathrm{e}-05$ & $49 \%$ \\
\hline c_86 & BAB09331 & 542 & unnamed protein product & Arabidopsis thaliana & $9.72 \mathrm{e}-03$ & $46 \%$ \\
\hline c_87 & ACJ11224 & 474 & vacuolar serine protease & Cladosporium cladosporioides & $2.88 \mathrm{e}-07$ & $77 \%$ \\
\hline c_88 & & 145 & No significant similarity found & & & \\
\hline c_9 & & 349 & No significant similarity found & & & \\
\hline
\end{tabular}


To validate the presence of some of these transcripts in $G$. intraradices $\mathrm{BE} 3$ and determine their temporal pattern of expression, we conducted reverse-transcriptase PCR (RT-PCR) in a random group of genes at different developmental phases during the establishment of the AM symbiosis (Figure 1 and Supplementary Table 2). These phases include fungal spores at the time of germination (asymbiotic phase), germinated spores during early hyphal growth (pre-symbiotic phase), initial penetration of fungal hyphae into plant roots prior to the appearance of arbuscular structures (symbiotic phase), and fully established AM symbiosis showing external hyphae with second generation spores and well developed arbuscular structures within plant roots (extradical phase). Most genes were expressed either before or at the time of spore germination, confirming that all of them are transcribed during the presymbiotic phase of hyphal growth. Whereas most transcripts could also be detected during the extradarical phase of the life cycle, only 2 out of 8 were expressed at symbiosis, suggesting that an important shift in gene expression distinguishes the pre-symbiotic and symbiotic phases. These results indicate that transcripts identified in our presymbiotic cDNA library are expressed in germinating spores of $G$. intraradices $\mathrm{BE} 3$.

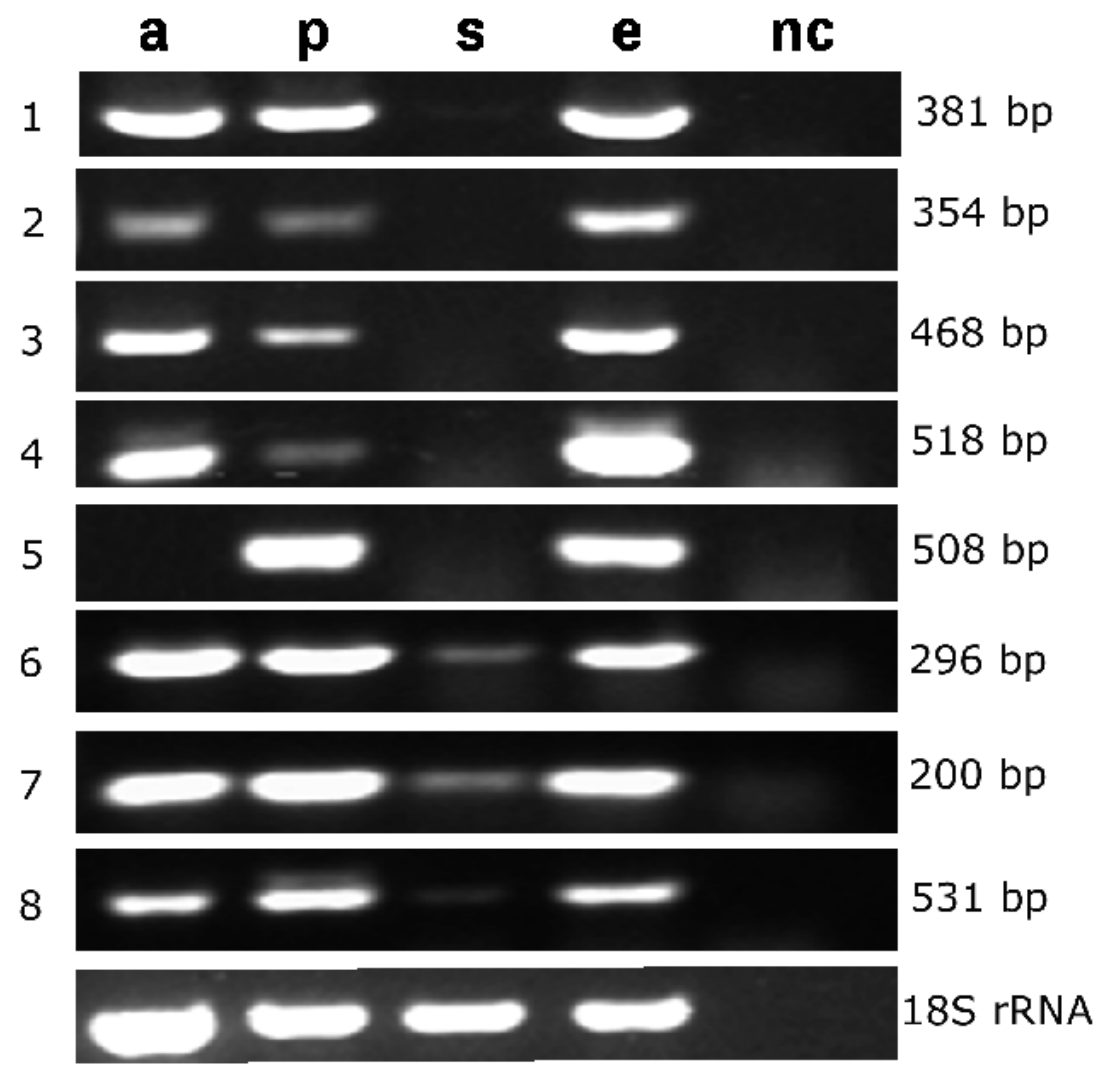

Figure 1. RT-PCR of genes expressed during the $G$. intraradices BE3 life cycle. cDNA amplification was performed during the asymbiotic (a), presymbiotic (p), symbiotic (s), and extraradical (e) phase of the fungal life cycle (see text for details), and (nc) negative control. (1) Hypothetical Protein homologue of Cryptococcus neoformans XP570866.1; (2) Hypothetical Protein homologue of Schizosaccharomyces pombe NP594031.1; (3) Hypothetical Protein homologue of Caenorhabditis briggsae CAE71635.1; (4) Hypothetical Protein homologue of Coprinopsis cinerea EAU86123.); (5) Hypothetical Protein homologue of Botryotinia fuckeliana XP001557861.1; (6) Hypothetical Protein homologue of Coprinopsis cinerea EAU88851.1; (7) Hypothetical protein with no significant homology; (8) Hypothetical Protein homologue of Yarrowia lipolytica XP502676.1. 
Supplementary Table 2. Primer sequence, annealing temperatures, and predicted size of amplification products described in this study.

\begin{tabular}{|c|c|c|c|c|}
\hline Primer name & Sequence & Temperature $\left({ }^{\circ} \mathbf{C}\right)$ & Size (bp) & Reference \\
\hline PBR42f & TACACTTTATGCTTCCGGCTC & 60 & 136 & \\
\hline PBR42r & AGCACACTGGCGGCCGTTAC & 60 & 130 & Inis study \\
\hline $\mathrm{fBC} 2$ & ACACTTTATGCTTCCGGCTC & & & \\
\hline $\mathrm{rBC} 2$ & AGCATATGGGAGCCGATCAG & 60 & 246 & This study \\
\hline $18 \mathrm{~S}$ fGi* & ACGACACCGGAGAGGGAGCC & 60 & 107 & \\
\hline $18 \mathrm{~S} \mathrm{rGi*}$ & CGGCTGCTGGCACCAGACTT & 60 & 191 & I his study \\
\hline phzfD* & TCGTTCATGCTGCCAGGTTG & 60 & 152 & This study \\
\hline phzrD* & CTGCTGGTGCATGACATGCA & & & \\
\hline rD1 & AAGGAGGTGATCCAGCC & 55 & 1500 & Weisburg et al., 1991 \\
\hline FD1 & AGAGTTTGATCCTGGCTCAG & & & \\
\hline RCNN3c & CCAGTATCCATTCAAAATAC & 59 & 381 & This study \\
\hline FCNN3c & GAAACTTGGCTTGAAGGTTG & & & \\
\hline RSP44 & TGATCGCTCGTCAGTTATC & 59 & 354 & This study \\
\hline FSP44 & CGGCAGACATGAATTGAAG & & & \\
\hline RCB47 & CTGCGAACCATGTCATCAG & 59 & 468 & This study \\
\hline FCB47 & GCAACAAATCAACTTCTCC & & & \\
\hline RCCO60 & CTTTATATTCAGTCTGCGC & 59 & 518 & This study \\
\hline FCCO60 & CGTTTGTTCAAACGGTTCC & & & \\
\hline RBF79 & GTAAGTGTAATGAGGAGAC & 59 & 508 & This study \\
\hline FBF79 & CATTGGAATGGCCATAAG & & & \\
\hline RCCO55 & GTCCTGGCCAATACATTTAC & 55 & 296 & This study \\
\hline FCCO55 & ССАТСТTTTAGACTTCATC & & & \\
\hline Rno71 & GAGTATGTATTTATACCAC & 55 & 200 & This study \\
\hline Fno71 & CAAAGAGCTAAGCTAATAAG & & & \\
\hline RYL129 & CGACACCTAATTTCAAAGC & 59 & 531 & This study \\
\hline FYL129 & CGTTAACTAAGCAATGGA & & & \\
\hline
\end{tabular}

\section{Expression of GintPbr1a, a gene encoding a protein homolog of}

\section{Phenazine Biosynthesis Regulator (Pbr)}

We identified a cDNA clone with high homology to Phenazine Biosynthesis Regulator (Pbr), a transcription regulator of the Burkholderia cenocepacia complex required for the expression of $p h z D$ and $p h z F$, two genes encoding proteins with significant homology to Pseudomonas choloroaphis $\mathrm{PhzD}$ and PhzF and involved in phenazine biosynthesis. We named this sequence GintPbr1a (for Glomus intraradices Pbr protein 1a; Franken P. 2002). The cDNA includes a transcript sequence corresponding to a 57 -amino acid residue containing a predicted helix-residue-helix motif that is commonly found on prokaryotic transcriptional regulators of Burkholderia cenocepacia (Figure 2A). At the amino acid level, both sequences only differ at Pbr amino acid positions 27 , in which glycine $(G)$ is replaced by alanine (A), and positions 29 to 32, in which an arginine-valinevaline $(\mathrm{R}-\mathrm{V}-\mathrm{V})$ motif is replaced by threonine-isoleucine-glycine- isoleucine (T-I-G-I). The strong conservation of the amino acid sequence between Pbr and GintPbrla suggested that both proteins could play equivalent biochemical roles, despite being present in bacteria with highly divergent biological habits.

To confirm the expression of GintPbrla within cells of $G$. intraradices BE3 and determine its temporal pattern of activity, we conducted RT-PCR at previously described developmental phases during the establishment of the AM symbiosis. GintPbrla was abundantly expressed at the presymbiotic phase and weakly at the extraradical phase, but not in the asymbiotic or symbiotic phase (Figure 2B), suggesting that its expression is mainly restricted to initial stages of hyphal growth, before the establishment of the AM symbiosis. These results validated the expression of the Burkholderia $\mathrm{Pbr}$ homolog in $G$. intraradices $\mathrm{BE} 3$, and indicated that its transcriptional activity occurs mainly during the presymbiotic phase of the fungal life cycle. 

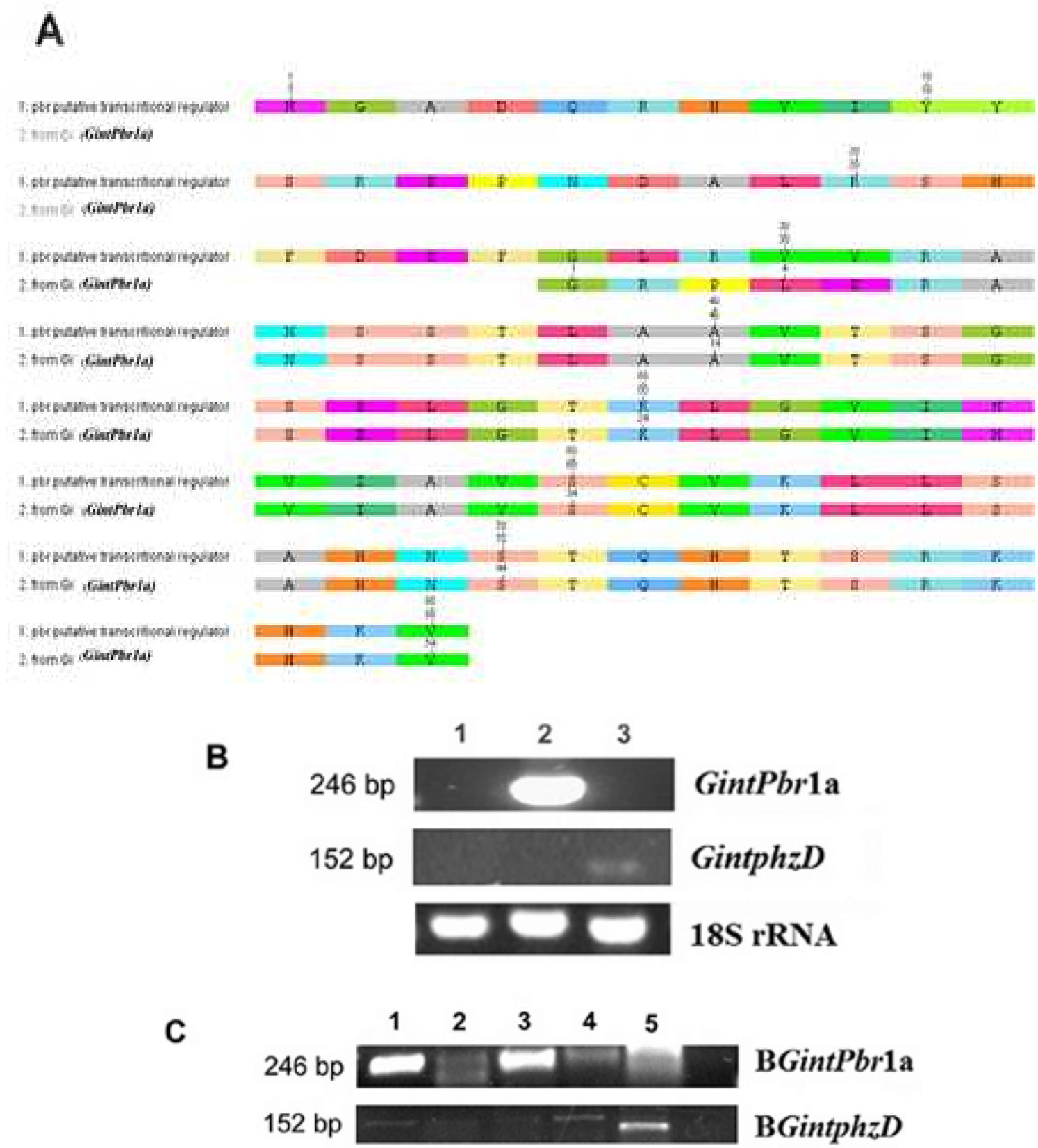

Figure 2. Expression of a phenazine biosynthetic pathway in endocellular bacteria of Glomus intraradices BE3. (A) Predicted amino acid alignment of GintPbr1a of G. intraradices BE3 and Pbr of Burkholderia cenocepacia. (B) RT-PCR expression of GintPbrla and BGintphzD in G. intraradices BE3; cDNA amplification was performed during the asymbiotic (1), presymbiotic (2) and, symbiotic (3), phase of the fungal life cycle (see text for details). (C) Genomic PCR amplification of BGintPbr1 (for bacterial GintPbrla) and BGintphzD (for bacterial GintphzD) in a bacteria isolated from spores of G. intraradices BE3. Whereas lane 1 represents the isolate BG1 from $G$. intraradices BE3, lanes 2 to 5 represent isolates BG3, BG4, BG7 and BG10 from G.margarita BE2, respectively. 
Bacterial isolates from in vitro cultivated $G$. intraradices spores express genes involved in phenazine biosynthesis

The molecular nature and the pattern of expression of GintPbrla suggested that the corresponding gene could have a bacterial origin within the AM fungus considering that the cDNA library was generated using polyadenylated primers that can potentially target prokaryotic transcripts present within spores and hyphae. To determine if the genome of a potential bacterial symbiont could contain a GintPbrla gene, we isolated bacterial cultures originating from sterilized spore inocula of G. intraradices BE3, and of Gigaspora margarita BE2 under in vitro culture and variable $\mathrm{pH}$ conditions. Whereas one bacterial isolate could be recovered from $G$. intraradices BE3 ( $\mathrm{pH}$ range from 4 to 7), four were recovered from G. margarita BE2 (pH range from 4 to 9). After the extraction of sufficient DNA from these isolates, and to attempt their taxonomic identification, we amplified and sequenced PCR products of approximately $1.5 \mathrm{~kb}$ corresponding to the conserved genomic DNA 16S ribosomal subunit (Table 2; Weisburg et al., 1991). Comparison to publicly available genomic databases revealed that the isolate recovered from $G$. intraradices BE3 corresponds to a previously described "uncultured bacteria" that we named BG1, whereas isolates from G. margarita BE2 correspond to presumed Brevibacillus sp. (BG10), Paenibacillus sp. (BG4), and two uncultured bacterium (BG3 and BG7), respectively.

To find if some of these bacteria could include a
GintPbrla copy in their genome, we attempted the amplification of a $246 \mathrm{bp}$ fragment using genomic DNA from all 5 previously cultivated bacterial isolates. A PCR product of the correct size was only amplified from BG1, the bacterial isolate from $G$. intraradices BE3. (Figure 2C). PCR products derived from BG4 and BG10 were also amplified, but their molecular size did not correspond to the predicted GintPbrla fragment, indicating that a different genomic version of a $\mathrm{Pbr}$ like gene could be present in the genome of some G. margarita BE2 endosymbionts. We also conducted genomic PCR amplification with primers specific to $p h z D$, a gene that is under transcriptional control of $\mathrm{Pbr}$ in Burkholderia. As expected, a PCR product was amplified in BG1 (Figure 2C), confirming that key regulatory enzymes of the phenzine biosynthetic pathway are encoded in the genome of bacteria isolated from in vitro cultures of $G$. intraradices BE3 spores. A PCR product was also derived from BG7 and BG10, confirming that isolates from G. margarita BE2 are also likely to express the same pathway. Finally, we conducted RT-PCR to determine if $G$. intraradices BE3 could express a homologue of $p h z D$, a gene encoding a protein $\mathrm{D}$ isochorismatase phenazine biosynthetic enzyme involved in the pathway of pyocianin (Komatsu et al., 2003). As shown in Figure 2B, a gene encoding a $p h z D$ ortholog is expressed at the symbiotic phase, confirming that a phenazine transcriptional regulatory pathway is active in $G$. intraradices BE3.

Table 2. Identification of bacteria derived from spores of $G$. intraradices BE3 and G. margarita BE2.

\begin{tabular}{ccccccc}
\hline Name & $\begin{array}{c}\text { Lenth } \\
(\mathbf{p b})\end{array}$ & $\begin{array}{c}\text { Phylogenetic relationship and } \\
\text { GenBank accession number }\end{array}$ & Isolated from & $\begin{array}{c}\text { Similarity } \\
\%\end{array}$ & E-value & Identity \% \\
\hline BG10 & 1523 & $\begin{array}{c}\text { Brevibacillus centrosporus } \\
\text { (AB112719.1) }\end{array}$ & G. margarita & 97 & 0.0 & 99 \\
BG4 & 1575 & $\begin{array}{c}\text { Paenibacillus graminis } \\
\text { (AB428571.1) } \\
\text { Uncultured bacterium } \\
\text { BG3 }\end{array}$ & G. margarita & 98 & 0.0 & 98 \\
BG7 & 1523 & $\begin{array}{c}\text { G. margarita } \\
\text { Uncultured bacterium } \\
\text { (EU560794.1) }\end{array}$ & G. margarita & 98 & 0.0 & 9.0 \\
BG1 & 1524 & Uncultured bacterium GU223217.1 & G. intraradices & 100 & 0.0 & 96 \\
\hline
\end{tabular}




\section{DISCUSSION}

To explore the molecular mechanisms that prevail during the establishment of the AM symbiosis involving the genus Glomus, we initiated a systematic global expression analysis of early phases of the $G$. intraradices life cycle. The large amount of expressed genes found at presymbiotic stages confirmed that fungal cells are active during early hyphal growth, and contain a wide diversity of transcripts with homology to eukaryotic and prokaryotic genes. While some of the identified transcripts with homology to prokaryotic genes (such as a sulfotransferase, a pyrophosphastase, and several reductases) could reflect global housekeeping functions related to the general metabolism, other expressed genes such as a $\mathrm{G}$ protein with a DNA binding domain, a high affinity $\mathrm{Zn}$ transporter, or a nitrogen metabolism negative regulator, could suggest that a cross-talk between trancriptionally active bacterial cells and fungal cells occurs early during the fungal life cycle. While a large group of hypothetical and unknown proteins requires further annotation and functional elucidation, additional prokaryotic expressed genes include those related to the biosynthesis of essential components such as amino acids, and those involved in the protection against potential pathogens or the production of antibiotics.

Phenazines are secondary metabolites of bacterial origin that have been implicated in the control of plant pathogens, contributing to the ecological fitness and pathogenicity of the producing strains. While the evolution and distribution of phenazine genes has revealed that they are mainly found in soil-dwelling or plant associated bacterial species (Mavrodi et al., 2010), their presence in the genome of AM fungal species had not been reported. The establishment of a $\mathrm{pH}$ gradientbased protocol allowed the isolation of bacterial colonies from G. intraradices BE3 spores. Although endocellular bacteria have not been reported in $G$. intraradices, this type of endosymbionts have been reported in other Glomus species (Naumann et al., 2010). The identification of a numerous transcripts with homology to eukaryotic genes, associated to the recovery of bacterial colonies from spores, suggests that $G$. intraradices BE3 indeed could contain bacterial cells within hyphae. While their taxonomic identification remains elusive, successful cultivation and DNA extraction confirmed that both $P b r$ and $p h z D$ homologs are present in genomic DNA extracted from $G$. intraradices spores and its associated bacterial isolates.

Our overall results indicate that a phenazine biosynthetic pathway is active during the G. intraradices BE3 life cycle.

They also suggest that this pathway is not exclusive of $\mathrm{G}$. intraradices, but is also active in G. margarita. As in previous studies of the biochemical mechanisms that regulate phenazine biosynthesis in Burholderia and Pseudomonas (Laursen et al., 2004; Mavrodi et al., 2001; Parsons et al., 2004), GintPbr1a is transcriptionally active at developmental stages that precede the expression of $\operatorname{Gintph} z$, a result in agreement with the role of GintPbrla as a pleiotropic transcriptional regulator necessary for the activation of phenazine biosynthetic enzymes (Ramos et al., 2010), presuming that GintPbrla transcripts precede the translation of the corresponding protein at subsequent developmental stages. Interestingly, initial expression of GintphzD occurs at the onset of the establishment of the fungal-plant symbiotic interaction, suggesting that phenazine production could play a role a later stages of the AM symbiosis establishment; however, a detailed molecular and biochemical analysis will be require to confirm the presence of endocellular bacteria in hyphal cells, as well as the presence of phenazines within roots before elucidating the physiological role of these molecules during AM symbiosis. Taken together, our results open new possibilities for using $G$. intraradices BE3 as a model system to study the molecular and biochemical mechanisms that allow the successful establishment of the tripartite AM symbiosis.

\section{ACKNOWLEDGEMENTS}

We thank Laila Partida Martínez for helpful comments on an earlier version of the manuscript, Rosalinda Serrato for help 
with maintenance of mycorrhizal fungi, and Rosa Maria Adame for technical assistance. D.G.L-M. was supported by a Ph.D. scholarship from Consejo Nacional de Ciencia y Tecnología (CONACyT) and Consejo Estatal de Ciencia y Tecnología de Guanajuato (CONCyTEG). Research was funded by CONACyT (V.O.P and J-Ph.V-C.), and the Howard Hughes Medical Institute International Scholar Program (JPh.V-C.).

\section{REFERENCES}

1. Anca, I.A.; Lumini, E.; Ghignone, S.; Salvioli, A.; Bianciotto, V.; Bonfante, P. (2009). The ftsZ gene of the endocellular bacterium Ca. Glomeribacter gigasporarum is preferentially expressed during the symbiotic phases of its host mycorrhizal fungus. Mol. Plant Microbe. Interact.22:301-10.

2. Bécard, G.; Piché, Y. (1992). Techniques for the Study of Mycorrhiza. Establishment of Vesicular-arbuscular Mycorrhiza in Root Organ Culture: Review and Proposed Methodology. In Techniques for the study of mycorrhiza. Edited by J. Norris, D. Read, and A. Varma. Academic Press, New York. pp. 89-108.

3. Bertaux, J.; Schmid, M.; Chemidlin Prevost-Boure, N.; Churin, J.L.; Hartmann, A.; Garbaye, J.; Frey-Klett, P. (2003). In situ identification of intracellular bacteria related to Paenibacillus spp. in the mycelium of the ectomycorrhizal fungus Laccaria bicolor S238N. Appl. Environ. Microbiol. 69:4243-4248.

4. Bianciotto, V.; Bandi, C.; Minerdi, D.; Sironi, M.; Volker Tichy, H.; Bonfante, P. (1996). An Obligately Endosymbiotic Mycorrhizal Fungus Itself Harbors Obligately Intracellular Bacteria. Appl. Environ. Microbiol. 62 (8): 3005-3010.

5. Bianciotto, V.; Lumini, E.; Lanfranco, L.; Minerdi, D.; Bonfante, P.; Perotto, S. (2000). Detection and Identification of Bacterial Endosymbionts in Arbuscular Mycorrhizal Fungi Belonging to the Family Gigasporaceae. Appl Environ Microbiol. 66(10): 4503-4509.

6. Bianciotto, V.; Genre, A.; Jargeat, P.; Lumini, E.; Bécard, G.; Bonfante, P. (2004). Vertical Transmission of Endobacteria in the Arbuscular Mycorrhizal Fungus Gigaspora margarita through Generation of Vegetative Spores. Appl. Environ.Microbiol. 70(6):3600-3608.

7. Bianciotto, V.; Lumini, E.; Lanfranco, L.; Minerdi, D.; Bonfante, P.; Perotto, S. (2000). Detection and Identification of Bacterial Endosymbionts in Arbuscular Mycorrhizal Fungi Belonging to the Family Gigasporaceae. Appl. Environ. Microbiol. 66 (10): 4503-4509.

8. Blankenfeldt, W.; Kuzin, P.A.; Skarina, T.; Korniyenko, Y.; Tong, L.; Bayer, P.; Janning, P.; Thomashow, S.L.; Mavrodi, V.D. (2004).
Structure and function of the phenazine biosynthetic protein $\mathrm{PhzF}$ from Pseudomonas fluorescens. PNAS.101 (47): 16431-16436.

9. Bonfante, P. (2003). Plants, mycorrhizal fungi and endobacteria: A dialog among cell and genomes. Biol. Bull. 204: 215-220

10. Bonfante, P.; Anca, I.A. (2009). Plants, Mycorrhizal Fungi, and Bacteria: A Network of Interactions. Annu. Rev. Microbiol. 63:363-83.

11. Delaney, M.S.; Dmitri, V.; Mavrodi, V.D.; Bonsall, F.R.; Thomashow, S.L. (2001). phzO, a Gene for Biosynthesis of 2-Hydroxylated Phenazine. Compounds in Pseudomonas aureofaciens 30-84. J Bacteriol. 183 (1): 318-327

12. Doner, W.L.; Bécard, G. (1991). Solubilization of gellan gels by chelation of cations. Biotechnology Techniques. 5 (1): 25-28.

13. Drummond, A.J.; Ashton, B.; Buxton, S.; Cheung, M.; Cooper, A.; Heled, J.; Kearse, M.; Moir, R.; Stones-Havas, S.; Sturrock, S.; Thierer, T.; Wilson, A. (2010). Geneious v5.3, Available from http://www.geneious.com

14. Fitzpatrick, D.A. (2009). Lines of evidence for horizontal gene transfer of a phenazine producing operon into multiple bacterial species. $J \mathrm{Mol}$ Evol. 68(2):171-85.

15. Fortin, A.J.; Bécard, G.; Declerck, S.; Dalpé, Y.; St-Arnaud, M.; Coughlan, P.A.; Piché, Y. (2002). Arbuscular mycorrhiza on root-organ cultures. Can. J. Bot. 80: 1-20.

16. Franken, P. (2002). A plea for a concerted nomenclature for AM fungal genes. Mycorrhiza. 12: 319.

17. Gerdemann, J.W.Y.; Nicholson, T.H. (1963). Spore of mycorrhizae endogone species extracted from soil by wet sieving and decanting. Trans Br. Mycol. Soc. 46: 235 - 244.

18. Harwood, C.R.; Cutting, S.M. (1990). Molecular biological methods for Bacillus. A Wiley Interscience Publication, Inglant.

19. Jargeat, P.; Cosseau, C.; Ola'h, B.; Jauneau, A.; Bonfante, P.; Batut, J.; Bécard, G. (2004). Isolation, free-living capacities, and genome structure of "Candidatus Glomeribacter gigasporarum," the endocellular bacterium of the mycorrhizal fungus Gigaspora margarita. J Bacteriol. 186 (20): 6876-84.

20. Komatsu, H.; Imura, Y.; Ohori, A.; Nagata, Y.; Tsuda, M. (2003). Distribution and Organization of Auxotrophic Genes on the Multichromosomal Genome of Burkholderia multivorans ATCC 17616. J. Bacteriol. 185 (11): 3333-3343.

21. Lackner, G.; Moebius, N.; Partida-Martinez, L.; Hertweck. Complete Genome Sequence of Burkholderia rhizoxinica, an Endosymbiont of Rhizopus microspores. J. Bacteriol. 193 (3): 783-784

22. Laursen, B.J.; Nielsen, J. (2004). Phenazine natural products: Biosynthesis, synthetic analogues, and biological activity. Chem. Rev. 104: 1663-1685.

23. Lumini, E.; Bianchiotto, V.; Jargeat, P.; Noveno, M.; Salvioli, A.; Faccio, A.; Becard, G.; Bonfante, P. (2007). Presymbiotic growth and 
sporal morphology are effected in the arbuscular mycorrhizal fungus Gigaspora margarita cured of its endobacteria. Cell Microbiol. 9(7): 1716-1729.

24. Macdonald, M.R.; Chandler, R.M. (1981). Bacterium-like organelles in the vesicular-arbuscular mycorrhizal. New Phytol. 89: 241-246.

25. Martin, F.; Aerts, A.; Ahrn, D.; Brun, A.; Danchin, J.G.E.F.; Duchaussoy, F.J.; Gibon, J.; Kohler, A.; Lindquist, E.; Pereda, V.; Salamov, A.; Shapiro, J.H.; Wuyts, J.; Blaudez, D.; Bue Brokstein, P.M.; Canbck, B.; Cohen, D.; Courty, E.P.; Coutinho, M.P.; Delaruelle, C.; Detter, J.C.; Deveau, A.; Difazio, S.; Duplessis, S.; Fraissinet-Tachet, L.; Lucic, E.; Frey-Klett, P.; Fourrey, C.; Feussner, I.; Gay, G.; Grimwood, J.; Hoegger, J.P.; Jain, P.; Kilaru, S.; Labb, J.C.Y.; Legu, V.; Le Tacon, F.; Marmeisse, R.; Melayah, D.; Montanini, B.; Muratet, M.; Nehls, U.; Niculita-Hirzel, H.; Oudot-Le Secq, M.P.; Peter, M.; Quesneville, H.; Rajashekar, B.; Reich, M.; Rouhier, N.; Schmutz, J.; Yin, T.; Chalot, M.B.; Henrissat, B.; Kes, U.; Lucas, S.; Van de Peer, Y.; Podila, K.G.; Polle, A.; Pukkila, P.J.; Richardson, P.M.; Rouz, P.; Sanders, I.R.; Stajich, J.E.; Tunlid, A.; Tuskan, G.; Grigoriev, V.I. (2008). The genome of Laccaria b.icolor provides insights into mycorrhizal symbiosis. Nature 452, 88-92.

26. Mavrodi, D.V.; Bonsall, F.R.; Delaney, M.S.; Soule, J.M.; Phillis, G.; Thomasshow, L.S. (2001). Functional Analysis of Genes for Biosynthesis of Pyocyanin and Phenazine-1 Carboxamide from Pseudomonas aeruginosa PAO1. J.Bact. 183(21): 6454-6465.

27. Naumann, M.; SchuBler, A.; Bonfante, P. (2010). The obligate endobacteria of arbuscular mycorrhizal fungi are ancient heritable components related to the Mollicutes. The ISME Journal. 4: 862-871.

28. Parsons, J.F.; Calabrese, K.; Eisenstein, E.; Ladner, J.E. (2004). Structure of the phenazine biosynthesis enzyme PhzG. Acta Cryst. D60, 21102113.

29. Partida-Martinez, L.P.; Hertweck, C. (2005). Pathogenic fungus harbours endosymbiotic bacteria for toxin production. Nature 437: 884-888.

30. Partida-Martinez, L.P.; Groth, I.; Schmitt, I.; Richter, W.; Roth, M.; Hertweck, C. (2007). Burkholderia rhizoxinica sp. nov. y Burkholderia endofungorum sp. nov., bacterial endosymbionts of the plant pathogenic fungus Rhizopus microsporus. Int. J. Syst. Evol. Microbiol. 57 (11):
2583-2590.

31. Ramos, C.G.; Sousa, S.A.; Grilo, A.M.; Eberl, L.; Leitão, J.H. (2010). The Burkholderia cenocepacia K56-2 pleiotropic regulator $\mathrm{Pbr}$, is required for stress resistance and virulence. Microb Pathog. 48(5):16877.

32. Ruiz-Lozano, M.J.; Bonfante, P. (1999). Identification of a putative Ptransporter operon in the genome of a Burkholderia strain lyving inside the arbuscular mycorrhizal fungus Gigaspora margarita. J. Bacteriol. 181 (13): 4106-4109.

33. Schüssler, A.; Schwarzott, D.; Walter, C. (2001). A new phylum, the Glomeromycota: phylogeny and evolution. Mycol. Res. 105: 1413-1421.

34. Smith, S.E.; Read, D.J. (1997). Mycorrizal symbiosis. 2nd edn. San Diego. USA. Academic Press.

35. Thomashow, L.S.; Weller, M.D. (1988). Role of a phenazine antibiotic from Pseudomonas fluorescens in biological control of Gaeumannomyces graminis var. tritici. J Bacteriol. 170(8): 3499-3508.

36. Van Buuren, L.M.; Lanfranco, L.; Longato, S.; Minerdi, D.; Harrison, M.J.; Bonfante, P. (1999). Construction and characterization of genomic libraries of two endomycorrhizal fungi: Glomus versiforme and Gigaspora margarita. Mycol Res. 103: 955-960

37. Weisburg, G.W.; Barns, S.M.; Pelletier, A.D.; Lane, J.D. (1991). 16S Ribosomal DNA Amplification for Phylogenetic Study. J Bacteriol. 173(2): 697-703.

38. White, J.T.; Bruns, T.; Taylor, J. (1990). Amplification and direct sequencing of fungal ribosomal RNA genes for phylogenetics. PCR protocols: a Guide to Methods and applications. 38: 315-322.

39. Worley, K.C.; Wiese, B.A.; Smith, R.F. (1995). BEAUTY: An enhanced BLAST-based search tool that integrates multiple biological information resources into sequence similarity search results. Genome Res. 5:173184.

40. Woyk, T.; Teeling, H.; Ivanova, N.N.; Huntemann, M.; Richter, M.; Gloeckner, F.O.; Boffelli, D.; Anderson, J.I.; Barry Shapiro, J.H.; Szeto, E.; Kyrpides, C.N.; Mussmann, M.; Amann, R.; Bergin, C.; Ruehland, C.; Rubi, M.E.; Dubilier, N. (2006). Symbiosis insights through metagenomic analysis of a microbial consortium. Nature 443: 950-955. 